\title{
Influenza A M2 Spans the Membrane Bilayer, Perturbs its Organization and Differentiates the Effect of Amantadine and Spiro[pyrrolidine-2,2'-adamantane] AK13 on Lipids
}

Athina Konstantinidi, ${ }^{a}$ Maria Chountoulesi, ${ }^{b}$ Nikolaos Naziris, ${ }^{b}$ Barbara Sartori, ${ }^{\mathrm{c}}$ Heinz Amenitsch, ${ }^{\mathrm{c}}$ Gregor Mali, ${ }^{\mathrm{d}}$ Tomaž Čendak, ${ }^{\mathrm{d}}$ Maria Plakantonaki, ${ }^{\mathrm{e}}$ Iro Triantafyllakou, ${ }^{\mathrm{e}}$ Theodore Tselios, ${ }^{\mathrm{e}}$ Costas Demetzos, David Busath, ${ }^{\mathrm{f}}$ Thomas Mavromoustakos ${ }^{\mathrm{g} *}$, Antonios Kolocouris, ${ }^{\mathrm{a}}$

${ }^{a}$ Section of Pharmaceutical Chemistry, Department of Pharmacy, School of Health Sciences, National and Kapodistrian University of Athens, Athens 15771, Greece

${ }^{\mathrm{b}}$ Section of Pharmaceutical Technology, Department of Pharmacy, School of Health Sciences, National and Kapodistrian University of Athens, Athens 15771, Greece

${ }^{c}$ Institute of Inorganic Chemistry, Graz University of Technology, Stremayrgasse 9/IV,A-8010 Graz, Austria

${ }^{\mathrm{d}}$ Department of Inorganic Chemistry and Technology, National Institute of Chemistry, Ljubljana SI-1001, Slovenia

${ }^{\mathrm{e}}$ Department of Chemistry, School of Natural Sciences, University of Patras, Rion, Patras 26500, Greece

${ }^{\mathrm{f}}$ Department of Physiology and Developmental Biology, Brigham Young University, Provo, UT 84602, USA

${ }^{\mathrm{g}}$ Section of Organic Chemistry, Department of Chemistry, National and Kapodistrian University of Athens, Athens 15771, Greece

\section{Corresponding Authors}

*E-mail: $\quad$ tmavrom@chem.uoa.gr (Thomas Mavromoustakos), ankol@pharm.uoa.gr (Antonios Kolocouris)

\section{Highlights}

- The investigation and observations made for the M2TM, excess aminoadamantane ligands in DMPC were made using the simpler version of biophysical methods including SDC, SAXS and WAXS, MD simulations and ssNMR.

- At low peptide concentrations of influenza A M2TM tetramer in DPMC bilayer, two lipid domains were observed that likely correspond to the M2TM boundary lipids and the bulk-like lipids. At high peptide concentrations, one domain was identified which constitute essentially all of the lipids which behave as boundary lipids. The influence of the M2TM on the DMPC bilayers without or with drug was evaluated by DSC and SAXS.

- ${ }^{1} \mathrm{H},{ }^{31} \mathrm{P}$ ssNMR and MD simulations, showed that M2TM in apo form or drug-bound form span the membrane interacting strongly with lipid acyl chain tails and the phosphate groups of the polar head surface. The MD simulations showed that the drugs anchor through their ammonium group with the lipid phosphate and occasionally with M2TM asparagine- 44 carboxylate groups. The ${ }^{13} \mathrm{C}$ ssNMR experiments allow the inspection of excess drug molecules and the assessment of its impact on the lipid head-group region.

- According to SAXS, WAXS, and DSC in the absence of M2TM both drugs exerted a similar perturbing effect on the bilayer at low concentrations, ie $x=0.05-0.08$. At the same concentrations of the drug when M2TM is present, the Amt and, to a lesser extent, $A K 13$ caused a significant disordering of chain stacking. Strikingly in a previous study it has been observed that both Amt and $A K 13$ perturb similarly the DMPC bilayers in DSC, by decreasing $T_{m}$, broadening DMPC bilayers half-width, and increasing $\Delta H$ at low concentrations, ie when $x=0.05$.This effect is likely due to the preference of $A K 13$ to locate in closer vicinity to M2TM compared to Amt as well as the stronger ionic interactions of Amt primary ammonium group with phosphate groups, compared with the secondary buried ammonium group in $A K 13$. 


\begin{abstract}
The effects in dimyristoylphosphatidylcholine (DMPC) bilayers of including the influenza A M2 protein transmembrane domain (M2TM) with or without an six-fold excess of amantadine (Amt) or the synthetic analog spiro[pyrrolidine-2,2'-adamantane] (AK13) were studied using differential scanning calorimetry (DSC), small- and wide-angle x-ray scattering (SAXS and WAXS), solid state NMR (ssNMR) and molecular dynamics (MD) simulations. The influence of the M2TM on the DMPC bilayers without or with drug was evaluated by DSC and SAXS. At low peptide concentrations, two lipid domains were observed that likely correspond to the M2TM boundary lipids and the bulk-like lipids. At high peptide concentrations, one domain was identified which constitute essentially all of the lipids which behave as boundary lipids. MD simulations, and ${ }^{1} \mathrm{H},{ }^{31} \mathrm{P}$ ssNMR showed that M2TM in apo form or drug-bound form span the membrane interacting strongly with lipid acyl chain tails and the phosphate groups of the polar head surface. The ${ }^{13} \mathrm{C}$ ssNMR experiments allow the inspection of excess drug molecules and the assessment of its impact on the lipid head-group region. The MD simulations showed that the drugs anchor through their ammonium group with the lipid phosphate and occasionally with M2TM asparagine-44 carboxylate groups. According to SAXS, WAXS and DSC, in the absence of M2TM both drugs exerted a similar perturbing effect on the bilayer at low concentrations. Interestingly, at the same concentrations when M2TM is present, the Amt and, to a lesser extent, $A K 13$ caused a significant disordering of chain stacking. This effect is likely due to the preference of $A K 13$ to locate in closer vicinity to M2TM compared to Amt as well as the stronger ionic interactions of Amt primary ammonium group with phosphate groups, compared with the secondary buried ammonium group in $A K 13$.
\end{abstract}

Keywords: aminoadamantane derivatives, DMPC bilayers, molecular dynamics, M2TM, solid state NMR, DSC, x-ray scattering 


\section{Introduction}

Biophysical experiments and MD simulations have been applied to explore the effects of drugs and their complexes with biologically relevant lipophilic protein receptors in lipid bilayers. ${ }^{1}$ The homotetrameric influenza A M2 protein is one of the simplest protein ion channels under investigation with M2TM spanning the lipid bilayer and consisting the ion channel pore (Figure 1). M2TM monomer is a lipophilic peptide with most of its lipophilic amino acid side chains orienting towards the hydrophobic core of the lipid bilayers or between adjacent helices. ${ }^{2-9}$ Aminoadamantane (Aamt) ligands bind inside the M2TM pore and block proton conduction, thereby preventing a continuation of the viral life cycle and abrogating pathogenesis. ${ }^{2-6}$ State-ofthe-art ssNMR, x-rays, ${ }^{8-17}$, MD simulations ${ }^{8-9,12}$ and other biophysical studies ${ }^{18-19}$ have been performed to investigate M2 protein structure and its complexes with Amt, rimantadine (Rim) and other Aamt derivatives. Conformational motions of M2TM without or with Aamt drugs were identified using ssNMR ${ }^{19-24}$ and described using $\mathrm{x}$-ray crystallography ${ }^{16-17}$ and provide the necessary plasticity that is needed for full biological function. ${ }^{23}$ The effect of drugs ${ }^{25}$ and the lipid environment on the conformation and function of M2 protein have been carefully studied. ${ }^{20-22,26}$ Among the lipid bilayers studied, it was found that DMPC is an optimal membrane bilayer for this system, compared to other glycerophospholipids. ${ }^{7,20-22,25-26}$ The reverse also has been investigated, focusing on understanding the effects of the M2 protein on membrane required for virus budding. These effects induce changes in the mobility and packing of the lipids and the curvature of the lipid bilayers. ${ }^{19,27-28}$

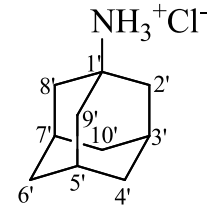

Amt

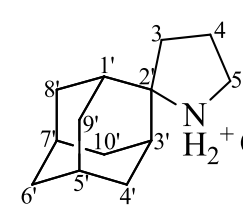

AK13

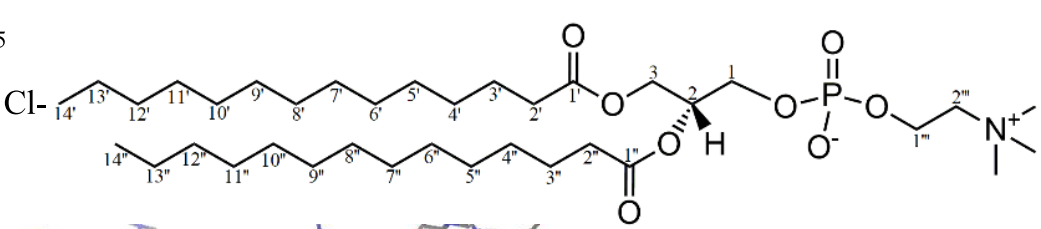

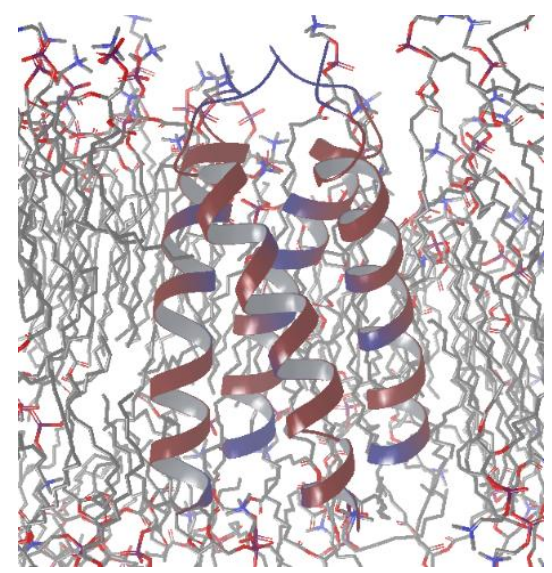

Figure 1. (up) Structures of Amt, AK13, and DMPC phospholipid; (down) a ribbons model of M2TM tetramer inside DMPC bilayers.

In a previous work, the effects of the M2 WT channel blockers Amt and AK13 on DMPC bilayers (Figure 1) were compared using DSC, $\mathrm{x}$-ray scattering, ssNMR spectroscopy, and MD simulations. ${ }^{29}$ It was found that the two drugs localized in the polar head area of the DMPC bilayers, stabilized through hydrogen bonding with sn-2 carbonyls in their amine form, and phosphate oxygens in their ammonium form. Such localization of the drugs explain their strong perturbing effect evidenced by all biophysical methodologies applied, and may be involved in a step for their insertion into M2 protein pore and effecting its conformational plasticity. 29

Although two-dimensional ssNMR and x-ray crystallography had been applied for the M2TM-Amt ${ }^{11}$, and M2TM-Rim ${ }^{15}$ complexes, and the full length M2-Rim complex ${ }^{30}$, in this work a combination of more easily accessible biophysical methods was adapted. In particular, DSC, SAXS/WAXS, and ${ }^{1} \mathrm{H},{ }^{13} \mathrm{C},{ }^{31} \mathrm{P}$ ssNMR and MD simulations were used to identify changes effected by M2TM tetramers without and with excess of Amt and its spiranic analogue AK13 on DMPC lipids at pH 8.0, in which M2TM forms tetramers ${ }^{31}$. 


\section{Materials and Methods}

\section{Materials}

Amt $(M w=187.7$; amantadine hydrochloride) was purchased from Merck Schuchardt OHG - Hohenbrunn, Germany and DMPC $(\mathrm{Mw}=677.9)$ from Avanti Polar Lipids, Inc, Alabaster, Alabama, USA. AK13 $(M w=$ 227.8; hydrochloride) was re-synthesized in our lab according to a previously reported procedure. ${ }^{32}$ The resin and Fmoc (9-fluorenylmethyloxycarboxyl) protected amino acids were obtained from Chemical and Biopharmaceutical Laboratories, Patras (BLP), Greece. All solvents and other reagents were purchased from Merck, Sigma-Aldrich and Fluka chemical companies.

\section{M2TM peptide synthesis}

The linear M2TM C-terminally amidated peptide, SSDPLVVAASIIGILHLILWILDRL-CONH ${ }_{2}$, corresponding to residues 22-46 of Udorn/72 wild type sequence of M2 protein was synthesized on 2chlorotrityl chloride resin conjugated with the Rink Amide linker, using the Fmoc/tBu solid-phase methodology and a standard synthetic protocol. ${ }^{33-37}$ The first $N^{\alpha}$ Fmoc - protected rink amide linker [4-[(2,4Dimethoxyphenyl)(Fmoc-amino)methyl]phenoxyacetic acid] was esterified to the resin in the presence of $N, N$-diisopropylethylamine (DIEA) in dichloromethane. The protected peptide was synthesized on the resin by sequential couplings of the appropriate Fmoc protected amino acids, in the presence of $N, N^{\prime}-$ diisopropylcarbodiimide (DIC) and 1-hydroxybenzotriazole (HOBT) in $N, N$-dimethylformamide (DMF). The Fmoc deprotection was achieved using $25 \%$ piperidine solution in $N, N$-dimethylformamide. The cleavage of the final protected peptide from the resin was carried out using dichloromethane / 2,2,2trifluoroethanol (7 / 3) solution. The trifluoroacetic acid (TFA) in dichloromethane (DCM) solution in the presence of scavengers (anisole, 1,2-ethanedithiole) was used for the final deprotection of the side chain protecting groups. The final unprotected crude M2TM peptide was purified by semi-preparative reverse phase high performance liquid chromatography and Nucleosil C-18 reversed phase analytical column $(250 \times$ $10 \mathrm{~mm}$ with $7 \mu \mathrm{m}$ packing material) using a procedure previously described ${ }^{38}$. A Waters system equipped with a $600 \mathrm{E}$ controller and a Waters 996 photodiode array UV detector was used while the analysis was controlled by a Millenium 2.1 operating system. The peptide purity, which was higher than 95\%, was assessed by analytical RP-HPLC (1260 Infinity, Quaternary Pump VL Agilent, Waldbronn, Germany) using an Agilent ZORBAX Eclipse Plus C18 column $(100 \times 4.6 \mathrm{~mm}$ with $3.5 \mu \mathrm{m}$ packing material $)$ and the identification of the M2TM peptide was achieved by ESI-MS $(M w=2727.3)$. Electron spray ionization mass spectrometry (ESI-MS) analysis was performed on a TSQ 7000 spectrometer (Electrospray Platform LC of Micromass) coupled to a MassLynx NT 2.3 data system.

\section{Sample preparation}

Samples were prepared by dissolving weighed amounts of dry DMPC lipid with M2TM peptide, Amt or AK13 in methanol. The mixture was then evaporated at room temperature under a gentle stream of argon and thereafter placed under vacuum for 24 hours in order to form a thin lipid film on the bottom of glass vials. The mixtures obtained were then fully hydrated at $\mathrm{pH} 8.0$ with aqueous buffer solution consisting of $\mathrm{Na}_{2} \mathrm{HPO}_{4} \cdot 2 \mathrm{H}_{2} \mathrm{O}$ and $\mathrm{NaH}_{2} \mathrm{PO}_{4} \cdot \mathrm{H}_{2} \mathrm{O}$ and vortexed to form multilamellar vesicles (MLVs). The samples studied have two molar concentrations of M2TM monomer in DMPC i.e., M2TM monomer per lipid molecule $(x=0.03)$ and $(x=0.06)$. These two samples correspond to M2TM monomer : DMPC molar ratios 1:30 and 1:16 and M2TM tetramer : DMPC molar ratios 1:120 and 1:64 respectively. Two mole ratios of drugs used, $x=0.05$ drug : 0.03 M2TM : 1 lipid and $x=0.08$ drug : 0.06 M2TM : 1 lipid, correspond to ratios of M2TM tetramer: Amt or $A K 13=3: 20$ and 3:16, both $\sim 1: 6$.

\section{DSC}

DSC thermograms of the MLVs were obtained by utilizing a DSC822 ${ }^{\mathrm{e}}$ Mettler-Toledo calorimeter (Schwerzenbach, Switzerland), calibrated with pure indium $\left(T_{m}=156.6^{\circ} \mathrm{C}\right)$. Sealed aluminum $40-\mu \mathrm{L}$ crucibles were used as sample holders. The systems under investigation were MLVs composed of DMPC, M2TM without or with Amt or AK13. Initially, around $5 \mathrm{mg}$ of dried sample was weighted and placed in a crucible, followed by hydration with $5 \mu \mathrm{L}$ of phosphate buffer. The crucible was sealed and vortexed for 5 -min. Then, the sample was left to equilibrate for a $15 \mathrm{~min}$ period prior to measurement. The reference for the measurement of every sample was an empty aluminum crucible. Heating-cooling cycles were performed repeatedly until reproducibility of the sample was achieved. The temperature range used was $10-40{ }^{\circ} \mathrm{C}$ and 
the scanning rate was $2.5{ }^{\circ} \mathrm{C} \mathrm{min}{ }^{-1}$. Before each cycle, the samples were equilibrated at a constant temperature of $10{ }^{\circ} \mathrm{C}$ for 10 minutes. The calorimetric data obtained (Table 1) i.e., the characteristic transition temperatures $T_{\text {onset, } m / s}$ and $T_{m / s}$, the enthalpy changes $\Delta H_{m / s}$ and the widths at half peak height of the $C_{p}$ profiles $\Delta T_{1 / 2, m / s}$ were analyzed using Mettler-Toledo STAR ${ }^{\mathrm{e}}$ software. The transition enthalpy for DMPC is expressed in units of $\mathrm{kJ} \mathrm{mol}^{-1}$ and is considered positive during an endothermic process.

\section{Solid state ${ }^{1} \mathrm{H}$ MAS, ${ }^{13} \mathrm{C}$ CP/MAS and ${ }^{31} \mathrm{P}$ static NMR spectroscopy}

${ }^{1} \mathrm{H}$ magic-angle spinning (MAS), ${ }^{13} \mathrm{C}$ cross polarization/magic-angle spinning $\left({ }^{13} \mathrm{C} \mathrm{CP} / \mathrm{MAS}\right)$ and ${ }^{31} \mathrm{P}$ static ssNMR spectra were recorded on a Varian $600 \mathrm{MHz}$ VNMRS spectrometer equipped with a $3.2 \mathrm{~mm} \mathrm{HX}$ MAS probe. Larmor frequencies for ${ }^{1} \mathrm{H},{ }^{13} \mathrm{C}$, and ${ }^{31} \mathrm{P}$ nuclei were $599.53,150.77$, and $242.70 \mathrm{MHz}$, respectively. In the ${ }^{1} \mathrm{H}$ MAS NMR experiment samples were spun with rotation frequency of $5 \mathrm{kHz}$, protons were excited with a 90-degree pulse of $2.3 \mu \mathrm{s}$, repetition delay was $5 \mathrm{~s}$, and 4 scans were co-added. In the ${ }^{13} \mathrm{C}$ $\mathrm{CP} / \mathrm{MAS}$ experiment, the polarization was transferred from protons to carbon nuclei in a $5 \mathrm{~ms} \mathrm{CP}$ block using Ramped-Amplitude on the proton channel, repetition delay between scans was $2 \mathrm{~s}$, and number of scans was 2000. Static ${ }^{31} \mathrm{P}$ Hahn-echo NMR spectra were obtained using a 90-degree pulse of $1.8 \mu \mathrm{s}$, a 180degree pulse of $3.6 \mu \mathrm{s}$, and an inter-pulse delay of $50 \mu \mathrm{s}$. Repetition delay was $5 \mathrm{~s}$ and 1000 scans were coadded. During acquisition of the ${ }^{13} \mathrm{C} \mathrm{CP} / \mathrm{MAS}$ and static ${ }^{31} \mathrm{P}$ signals, high-power proton decoupling was employed. The ${ }^{1} \mathrm{H}$ and ${ }^{13} \mathrm{C}$ chemical shift axes were referenced to tetramethylsilane, and the ${ }^{31} \mathrm{P}$ chemical shifts were reported relative to the phosphorus signal of $85 \% \mathrm{H}_{3} \mathrm{PO}_{4}$.

\section{X-ray scattering}

SAXS experiments were carried out at the Austrian SAXS beamline (Elettra Sincrotrone, Trieste, Italy) ${ }^{39}$. Two-dimensional Pilatus3 1M and Pilatus 100k detectors (Dectris Ltd, Baden, Switzerland) were used to collect SAXS and WAXS scattering pattern, respectively. For SAXS, the sample to detector distance was $1048 \mathrm{~mm}$. The $\mathrm{x}$-ray wavelength was $0.154 \mathrm{~nm}$ at a photon energy of $8 \mathrm{keV}$, covering a q-range between $0.095 \mathrm{~nm}^{-1}$ to $7.54 \mathrm{~nm}^{-1}$, where $\mathrm{q}$ is the magnitude of the scattering vector defined by $\mathrm{q}=4 \pi / \lambda \sin (\theta / 2)$, with $\lambda$ the wavelength and $2 \theta$ the scattering angle. For WAXS, the angular range covered corresponded to a qregime between $11.7 \mathrm{~nm}^{-1}$ and $21.2 \mathrm{~nm}^{-1}$. The angular scale of the SAXS and WAXS measured intensity was obtained using silver behenate $\left(\mathrm{CH}_{3}\left(\mathrm{CH}_{2}\right)_{20} \mathrm{COOAg}\right)$, with a d-spacing value of $5.838 \mathrm{~nm}$, and pbromobenzoic acid as calibration standards, respectively. The 2D images were integrated to $1 \mathrm{D}$ scattering functions with Fit2D, ${ }^{40}$ and analyzed with IGOR pro (Wavemetrics, Inc., Lake Oswego, OR) to calculate when possible the characteristic lattice distance. The samples were loaded in a glass capillary and inserted in a dedicated sample holder, which was thermostated with a water bath having a temperature stability of \pm 0.1 ${ }^{\circ} \mathrm{C}$ (Unistat CC, Huber, Offenburg, Germany). The static measurements were done at $20{ }^{\circ} \mathrm{C}$ and $30{ }^{\circ} \mathrm{C}$, acquiring 4 frames of $30 \mathrm{~s}$, with $2 \mathrm{~s}$ delay between each frame. The samples were equilibrated for a few minutes at each temperature before exposure. The bilayer model used and its applications were recently presented. ${ }^{41-42}$

\section{Simulations}

The MD simulations were conducted with Desmond. The M2TM tetramer in complex with Amt or AK13 and additional five molecules of the Aamt ligand, to resemble the ratio of the constituents used in the biophysical studies, were embedded in DMPC lipid bilayers. The Aamt ligand is in its ammonium form at $\mathrm{pH}$ 8.0. The DMPC lipids represent the optimal membrane mimetic system in this case ${ }^{26,43}$, having been used for the structure determination in 2KQT for retaining the proper M2TM structure compared to other glycerophospholipids. The DMPC lipid bilayer extended $20 \AA$ beyond the solutes in x,y axes, resulting in a system including 120 lipid molecules. The bilayer was solvated using $20 \AA$ thick layer of TIP3P waters ${ }^{44}$ for each leaflet. $\mathrm{Na}^{+}$and $\mathrm{Cl}^{-}$ions were placed in the water phase to neutralize the systems and to represent the experimental salt concentration of $0.150 \mathrm{M} \mathrm{NaCl}$. The total number of system's atoms reached $\sim 50000$. Membrane creation and system solvation were conducted with the "System Builder" utility of Desmond (Schrodinger, Cambridge, MA) ${ }^{45-46}$. For modeling the interactions, MD simulations were performed with both OPLS 2005 force field ${ }^{47-49}$ and Amber ff99SB ${ }^{50}$ force field, applied using the Viparr module of Desmond. Calculation of long-range electrostatic interactions, was utilized by the particle mesh Ewald method ${ }^{51-52}$, with a grid spacing of $0.8 \AA \hat{A}$. Van der Waals and short-range electrostatic interactions were smoothly truncated at $9.0 \AA$ A . A constant temperature was maintaned in all simulations using Nosé-Hoover thermostat, and the Martyna-Tobias-Klein method was employed to control the pressure ${ }^{53}$. Periodic 
boundary conditions were applied using a simulation box of $95 \times 70 \times 81 \AA^{3}$. Multistep RESPA integrator ${ }^{54}$ was used to integrate the equations of motion with an inner time step of $2 \mathrm{fs}$ for bonded interactions, and non-bonded interactions within a cut-off of $9 \AA$; an outer time step of 6.0 fs was used for non-bonded interactions beyond the cut-off. The default protocol provided by Desmond was modified in order to perform the MD simulations. The equilibration protocol consists of a series of restrained minimizations and MD simulations designed to relax the system, while not deviating substantially from the initial coordinates. Initially, two rounds of steepest descent minimization with a maximum of 2000 steps and harmonic restraints of $50 \mathrm{kcal} \mathrm{mol}^{-1} \AA^{-2}$ were applied on all solute atoms, followed by 10000 steps of minimization without restraints. The first simulation was run for $200 \mathrm{ps}$ at a temperature of $10 \mathrm{~K}$ in the NVT ensemble with solute heavy atoms restrained with a force constant of $50 \mathrm{kcal} \mathrm{mol}^{-1} \AA^{-2}$. The temperature was then raised during a 200 ps MD simulation to $325 \mathrm{~K}$ in the NVT ensemble with the force constant retained. The temperature of $325 \mathrm{~K}$ was used in the MD simulations in order to ensure that the membrane state is above the melting temperature state of $297 \mathrm{~K}$ for DMPC lipids. ${ }^{55}$ The heating was followed by equilibration runs. Three stages of NPT equilibration (1 atm) with restraints were performed, first with the heavy atoms of the system restrained for $1 \mathrm{~ns}$ and the second with solvent and lipid molecules restrained harmonically with a force constant of $10 \mathrm{kcal} / \mathrm{mol} / \AA^{2}$ for $10 \mathrm{~ns}$. In the third stage, the $\mathrm{C}_{\alpha}$ atoms of M2TM were harmonically restrained with a force constant of $2 \mathrm{kcal} / \mathrm{mol} / \AA^{2}$ for $1 \mathrm{~ns}$. The above-mentioned was followed by a $200 \mathrm{~ns}$ NPT simulation without restraints. Within this time, the total energy, system dimensions, and the RMSD reached a plateau, and the systems were considered equilibrated. For structural analyses, snapshots of the different systems were visualized with VMD ${ }^{56}$ or Maestro. ${ }^{57}$ Trajectories were analyzed with Maestro, Gromacs, ${ }^{58-59}$ and VMD. Measurements were done with Gromacs tools. For the calculation of hydrogen bonds, a cut-off angle of 30 degrees deviation from $180^{\circ}$ between the donor-hydrogen-acceptor atoms and a cut-off distance of $3.5 \AA$ between the donor and acceptor atoms were applied. The definition of boundary and non-boundary lipids was realized by the application of an algorithm which use Voronoi cells around protein atoms for the partition of the system ${ }^{60}$.

\section{Results and Discussion DSC results}

At the two concentrations of M2TM in fully hydrated DMPC at $\mathrm{pH} 8.0$ used in this research, $x=0.03$ and $x=0.06$ corresponding to M2TM tetramer : lipids ratio 1:120 and 1:64 respectively, M2TM forms quantitatively tetramers. ${ }^{26}$ The thermal effects of the M2TM tetramer at these concentrations and in presence of a six-molar excess of $A m t$ or $A K 13$ were studied. The calorimetric data for pure DMPC bilayers were in accordance with the previous literature data. ${ }^{61}$ In particular, there was a main sharp peak centered at 23.43 ${ }^{\circ} \mathrm{C}$, exhibiting a high-enthalpy transition, accompanied by a broad low-enthalpy pre-transition centered at $13.27^{\circ} \mathrm{C}$ (Figure 2a) which signals the onset of the ripple phase during heating ${ }^{62}$ and is more sensitive to disruption than the main transition. A thermal scan of the binary system DMPC + M2TM $(x=0.03)$ as it is shown in Figure $2 b$ is lacking the pre-transition but is still composed of two distinct peaks. The first domain (domain I) is a very broad small endothermic event centered approximately at $23{ }^{\circ} \mathrm{C}$ (Figure $2 \mathrm{~b}$, Table 1 ). The second major domain (domain II) contains also a broadened peak with $T_{\mathrm{m}}=20.60{ }^{\circ} \mathrm{C}$, about $3{ }^{\circ} \mathrm{C}$ lower from that observed by DMPC bilayers alone. The formation of the two domains was studied systematically with time and was found to be persistent although with some modifications in their intensities. It may be suggested that the low- $\mathrm{T}_{\mathrm{m}}$ domain (II) corresponds to bulk DMPC lipids with strongly cooperative phase transition, but destabilization of the gel phase through long range interactions. Domain I correspond to lipids bound to M2TM tetramers, which constitute essentially all of the lipids at high peptide density ( $x=0.06$, Figure 2e). Shifting and broadening of lipid phase transitions, as well as elimination of pre-transitions are commonly observed upon membrane-insertion of proteins, e.g. mellitin, defensins, and gramicidin S. ${ }^{28,63-65}$.

Adding Amt or $A K 13$ ( $x=0.05)$ in the mixture of DMPC + M2TM ( $x=0.03)$ affected both domains (Figure 2 c,d). Compounds $A m t$ and $A K 13$ did not differ appreciably in their effects at this concentration, $A K 13$ slightly more than Amt. Both molecules further decreased the $T_{\mathrm{m}}$ and $\Delta H_{\mathrm{m}}$ for the two domains. Interestingly, the presence of either drug resulted in decreasing the breadth of domain II and shifted the $T_{\mathrm{m}}$ of both domains to lower temperatures. The sample composition for Figures $2 \mathrm{c}$ and $2 \mathrm{~d}$ corresponds to one equivalent M2TM tetramer + six equivalents Amt or AK13 with 120 DMPC lipid molecules. It has been previously shown that when the sample composition is one equivalent M2TM tetramer + four equivalents Amt, one equivalent of the drug binds inside the high affinity binding site of the M2TM tetramer pore; it has been suggested that the excess of the drug, being concentrated in the lipid headgroup area, may interact with the four superficial D44 
carboxylate groups of M2TM in the inner leaflet, but with a 40-fold lower affinity than for the pore interior. 23,66 .

In the denser binary mixture DMPC + M2TM $(x=0.06)$, which corresponds to a sample composition including the M2TM tetramer in 64 DMPC lipids, a very broad peak was observed at $T_{\mathrm{m}}=22.8{ }^{\circ} \mathrm{C}$, being very close to that of the pure DMPC bilayers, but with $\Delta H_{\mathrm{m}}$ highly decreased and $\Delta T_{1 / 2}$ highly increased (Figure 2e). The second domain disappeared indicating that the M2TM is distributed uniformly in the lipid bilayers, such that at this density all lipids behave as boundary lipids. Interestingly, the two drugs in this lipid bilayer containing high-density M2TM cause different effects. In the ternary mixture DMPC + M2TM $(x=0.06)+$ Amt $(x=0.08)$ the DSC scan still may include two domains (or alternatively reinstates the pretransition upshifted to $\sim 15.2{ }^{\circ} \mathrm{C}$ ) (Figure $2 \mathrm{f}$ ). But if so, domain II is now almost absent or at least less prominent compared to the lower concentration sample M2TM $(x=0.03)+A m t(x=0.05)$ (Figure 2c). In fact, when the Aamt ligand is $A K 13$ the DSC scan resulted in only one domain (Figure $2 \mathrm{~g}$ ), similar to the single domain I of DMPC + M2TM ( $x=0.06)$ (Figure 2e), suggesting that the M2TM-AK13 complex and the excess AK13 constituents are uniformly distributed in the lipid bilayer. Thus, the sample including five equivalents $A K 13$, one equivalent M2TM-AK13 complex and 64 lipids did not produce a second domain compared to Amt, but it affects significantly only domain I by increasing $\Delta T_{1 / 2}$ and lowering $\Delta \mathrm{H}_{\text {cal }}$. Amantadine, having a primary ammonium group, can interact through stronger hydrogen bonds with phosphate oxygens of the polar head region in the bilayer, compared to $A K 13$, effecting more efficiently the formation of a second distinct domain II of bulk-like lipid. In contrast, with the more lipophilic $A K 13$ the spiro junction with adamantane buries the secondary ammonium group and hinders hydrogen bonding interactions. Indeed, it has been previously showed using $500 \mathrm{~ns}$ MD simulations that, although AK13 was also mainly localized in the polar head region, it could move easily between the two leaflets of the bilayer ${ }^{29}$.

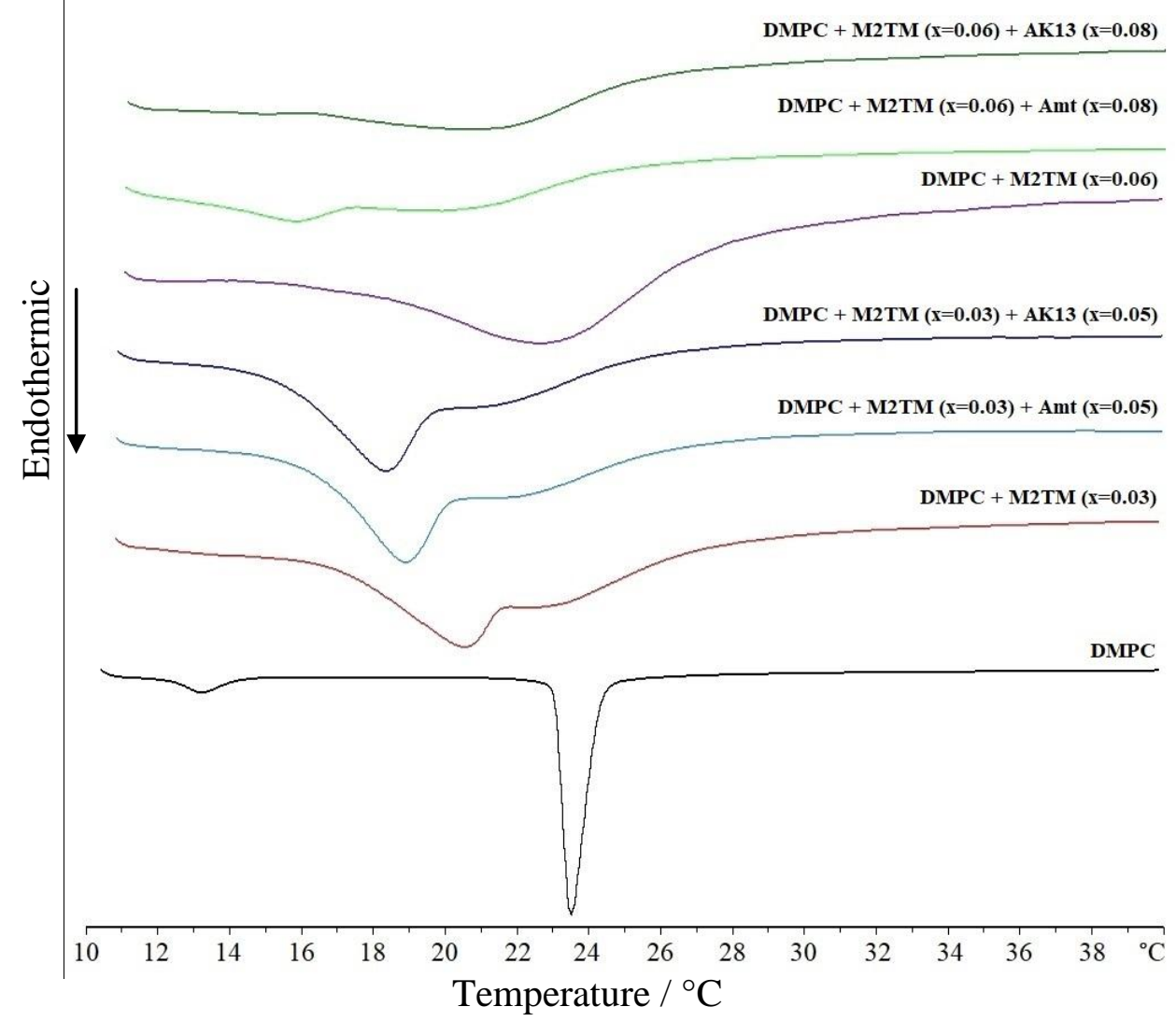

Figure 2. DSC heating scans of DMPC bilayers, fully hydrated in phosphate buffer $\mathrm{pH}$ 8, including M2TM tetramer and six-fold excess of the Aamt ligand. The range for the calculation of thermotropic parameters are from $10{ }^{\circ} \mathrm{C}$ to $40{ }^{\circ} \mathrm{C}$.

\section{Solid state NMR spectroscopy}

${ }^{1} H$ MAS NMR in the gel phase: The high resolution ${ }^{1} \mathrm{H}$ MAS NMR spectrum of DMPC fully hydrated bilayers at $\mathrm{pH} 8.0$ showed only eminent peaks at ca $3.0 \mathrm{ppm},{ }^{67}$ which were assigned to the N-methyl 
hydrogens of the lipid polar head-group (Figure 3, Table 2). The presence of M2TM $(x=0.03)$ at $15{ }^{\circ} \mathrm{C}$ caused fluidization of DMPC bilayers at $\mathrm{pH} 8.0$ as became evident from the appearance of peaks attributed to the alkyl chains $(0.5-1.7 \mathrm{ppm})$ in Figure 3 (left). Increasing the concentration of M2TM $(x=0.06)$ caused further fluidization of DMPC bilayers at $\mathrm{pH} 8.0$ as the alkyl chain region covered broader range (0.0-2.7 ppm) while a systematic shift of the peaks in the lower field was observed (Table 2).

The spectrum of the sample DMPC + M2TM $(x=0.03)+A m t(x=0.05)$ or $A K 13(x=0.05)$ (Figure 3, right) was similar to that of DMPC $+A m t(x=0.05)$ or $A K 13(x=0.05)$ (data shown in ref. $\left.{ }^{26}\right)$. Therefore, the drugs mask the effects of M2TM at 0.5-1.7 ppm in the NMR spectrum. Additionally, it has been reported that Aamt drugs bound to the M2TM pore reduce its conformational plasticity ${ }^{68}$ which is in agreement with the observed limited protein's effect on DMPC fluidization. When Amt or AK13 ( $x=0.08)$ and M2TM $(x=0.06)$ concentrations were used (Figure 3 right), the spectrum at $\mathrm{pH} 8.0$ appeared similar to that of DMPC + M2TM ( $x=0.03)$ (Figure 3 left), but the peaks intensities were increased, suggesting instead a higher fluidization of DMPC acyl chains in this case.

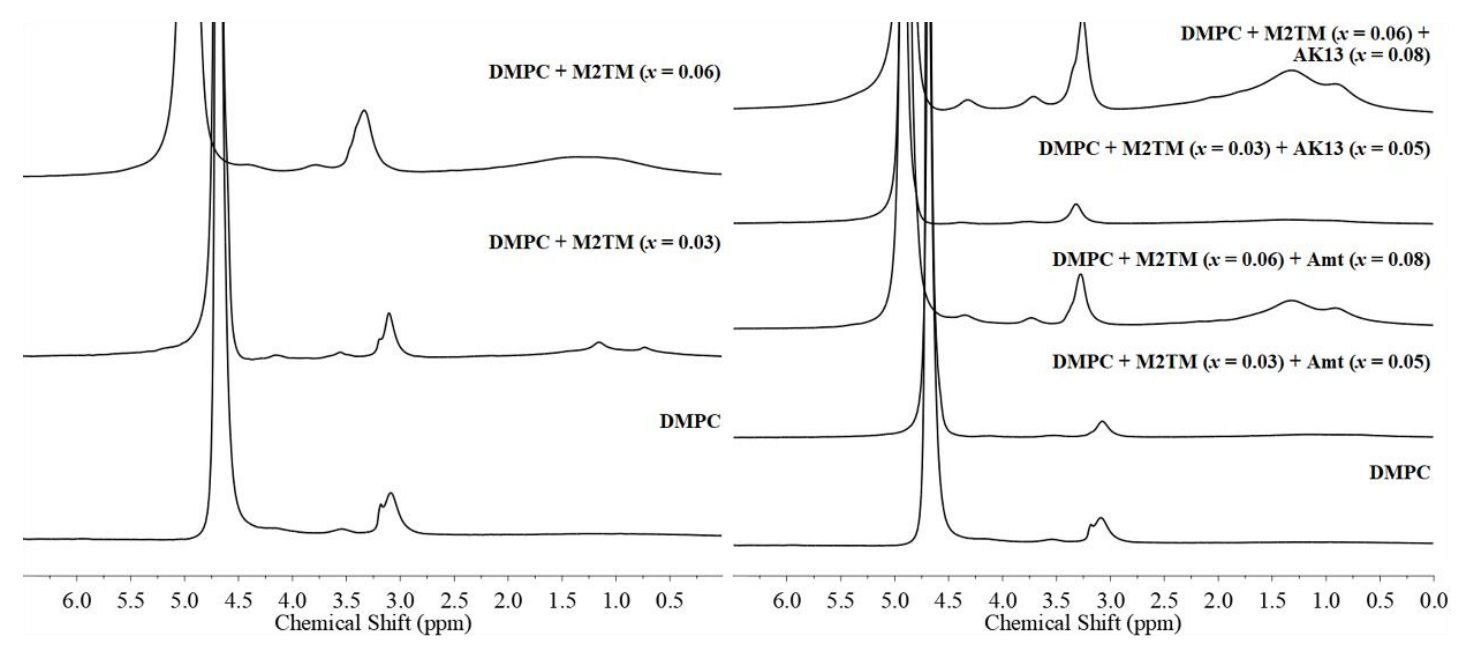

Figure 3. ${ }^{1} \mathrm{H}$ MAS NMR spectra of DMPC bilayers with M2TM (left) and with M2TM and Amt or AK13 (right) at $\mathrm{pH} 8.0$ and at $15^{\circ} \mathrm{C}$.

${ }^{13} \mathrm{C} C P /$ MAS NMR at gel phase: M2TM at concentration $x=0.03$ did not modify chemical shifts and intensities of DMPC bilayer peaks acquired at $\mathrm{pH} 8.0$; but did by 0-0.4 ppm at lower fields for the higher concentration of $x=0.06$ (Figure 4, upper traces). The methyl group of DMPC resonance at $\delta=14.4 \mathrm{ppm}$ in the same sample increased in intensity through cross polarization. When Amt or AK13 was incorporated at concentration $x=0.05$ (Figure 4, lower traces), peaks of DMPC at ca $14 \mathrm{ppm}$ and $54 \mathrm{ppm}$, which are susceptible to cross polarization effects, showed modified intensities. At higher concentrations of $x=0.08$, drugs shifted the chemical shifts by $0.2 \mathrm{ppm}$, most often towards the lower field (Table 3 ). The peaks from the drugs (see asterisks in Figure 4; Table 3) were already observed at the lower concentration of $x=0.05$ but were more eminent at the higher concentration of $x=0.08$. It has been observed that when a stoichiometric amount of Amt with M2TM tetramer is present, the spectrum resembled the lipid-only spectrum. ${ }^{14}$ Thus, the peaks in the bottom traces of Figure 4, are due to the excess of drug molecule not bound with M2TM distributed in the DMPC bilayers. These peaks of the drug showed chemical shift changes that ranged between 0.4 to $1.4 \mathrm{ppm}$ compared to the solution resonances suggesting an interaction of the drug with the membrane system (Table 4). 


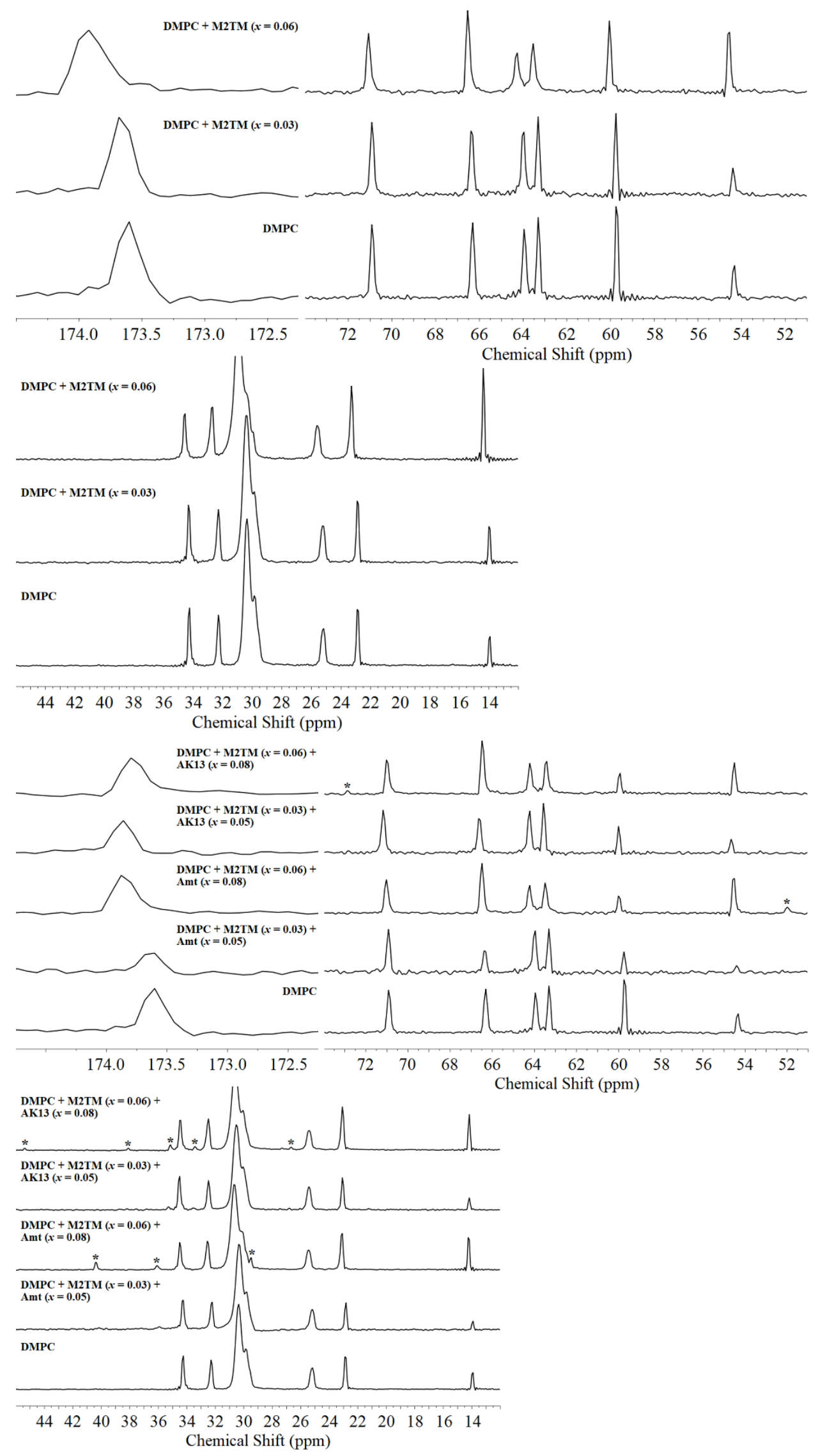

Figure 4. ${ }^{13} \mathrm{C}$ CP-MAS NMR spectra of DMPC bilayers with M2TM (upper traces) and with M2TM and Amt or $A K 13$ (lower traces) at $15^{\circ} \mathrm{C}$ and $\mathrm{pH} 8.0$.

${ }^{31} P$ static NMR spectroscopy at gel phase: The effects of M2TM incorporated in DMPC bilayers at $\mathrm{pH} 8.0$ on the phosphate group resonance at $c a-20 \mathrm{ppm}$ are shown in the static ${ }^{31} \mathrm{P}$ powder spectra (Figure 5). The 
narrow peaks in the ${ }^{31} \mathrm{P}$ spectra between 0 and $10 \mathrm{ppm}$ correspond to the phosphate groups of the buffer solution. It is evident that M2TM at $x=0.03$ caused a decrease in the difference in the components of the shielding tensor $\sigma_{\mathrm{II}}-\sigma_{\mathrm{I}}$ value by $c a 10 \mathrm{ppm}$ (Table 5). At the highest concentration of $x=0.06$, the $\sigma_{\mathrm{II}}-\sigma_{\mathrm{I}}$ value decreased further by $4 \mathrm{ppm}$. These results show that M2TM perturbs, as expected, the polar headgroup of the lipid bilayers as it spans the transmembrane region. According to ${ }^{31} \mathrm{P}$ NMR spectra, the ternary system DMPC + M2TM $(x=0.03)+A m t(x=0.05)$ or $A K 13(x=0.05)$ produced $\sigma_{\mathrm{I}}-\sigma_{\mathrm{II}}$ values almost identical to those of DMPC + M2TM ( $x=0.03)$ at the gel phase indicating that $A m t$ and $A K 13$ at concentration $x=0.05$ do not perturb further the phosphate groups region in the presence of M2TM. This is consistent with results from our previous paper ${ }^{29}$ showing that at these concentrations the drugs did not change $\sigma_{\text {II }}-\sigma_{\text {I }}$ value compared to pure DMPC. Only when the concentration of the drug was $x=0.08$ in the DMPC + Aamt system did the $\sigma_{\mathrm{I}}-\sigma_{\mathrm{II}}$ value increase by $4 \mathrm{ppm}$ compared to the pure DMPC. ${ }^{29}$ The ternary system DMPC + M2TM $(x=0.06)+A m t(x=0.08)$ or $A K 13(x=0.08)$ gives $\sigma_{\mathrm{I}}-\sigma_{\mathrm{II}}$ values increased by ca $3 \mathrm{ppm}$ compared to those of $\mathrm{DMPC}+\mathrm{M} 2 \mathrm{TM}(x=0.06)$ at the gel phase temperature of $15^{\circ} \mathrm{C}$.

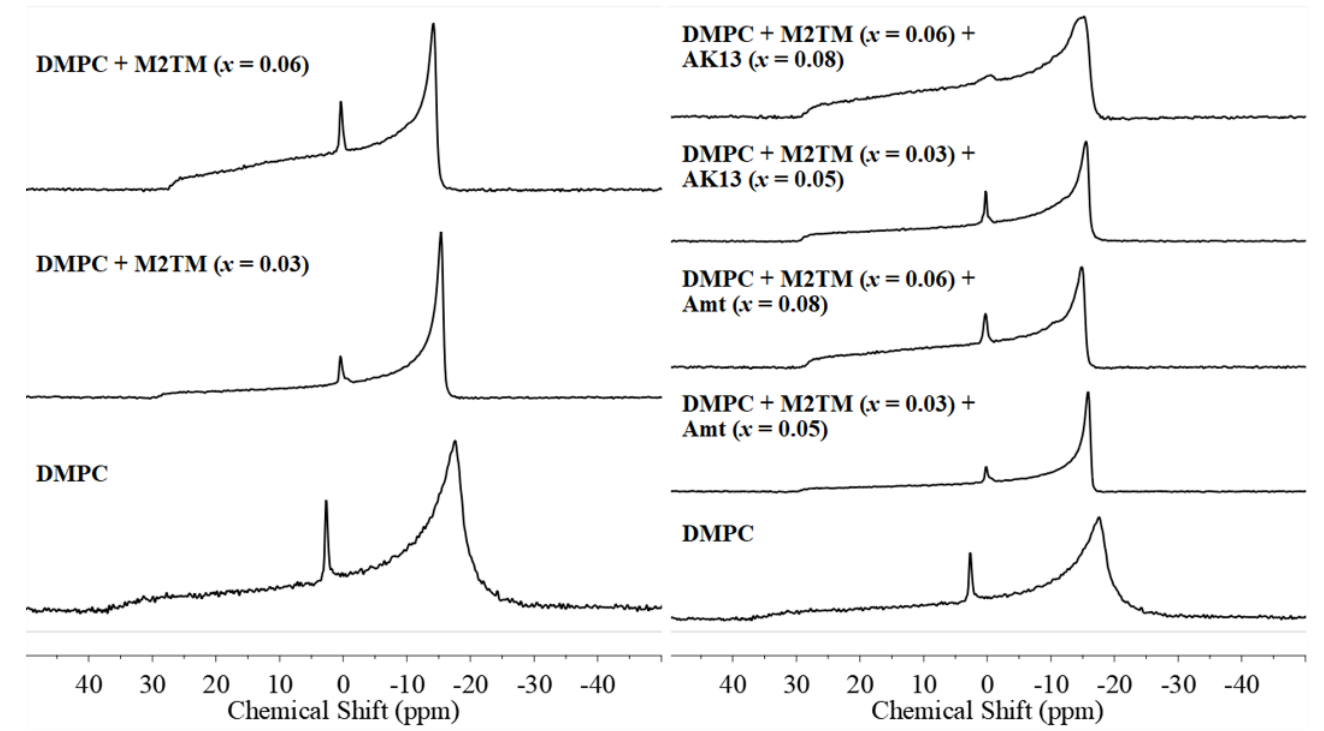

Figure 5. ${ }^{31} \mathrm{P}$ NMR spectra of DMPC bilayers with M2TM (left) and with M2TM and Amt or AK13 (right) at $15^{\circ} \mathrm{C}$ and $\mathrm{pH} 8.0$.

${ }^{1} H$ MAS NMR at liquid crystalline phase: The effects of M2TM in DMPC bilayers at the liquid crystalline phase $\left(35^{\circ} \mathrm{C}\right)$ at $\mathrm{pH} 8.0$ using the same two concentrations as in the gel phase are shown in Figure 6 (left). At $x=0.03$ M2TM have no observable effect on the DMPC bilayers spectrum, suggesting that the protein is embedded in the lipid bilayer and does not significantly affect its dynamics. At the higher concentration of $x=0.06$ the intensities of the peaks grow, and the resonances are shifted to the lower field (Table 6). The preparations DMPC + M2TM $(x=0.03)+A m t(x=0.05)$ or AK13 $(x=0.05)$ and DMPC + M2TM $(x=0.06)+$ Amt $(x=0.08)$ or $A K 13(x=0.08)$ resemble those of DMPC + M2TM $(x=0.03)$ and DMPC + M2TM $(x=0.06)$ correspondingly. As discussed previously in these two preparations the Aamt drug is inserted in the M2TM pore and the excess of molecules is distributed mainly in the bilayers. The observance of peaks with identical linewidths as those reported in our previous publication ${ }^{29}$ where drugs perturbed DMPC bilayers not containing M2TM is an indication that Aamt drugs insert into and affect the lipid bilayer (see asterisks in Figure 6; Table 7). 


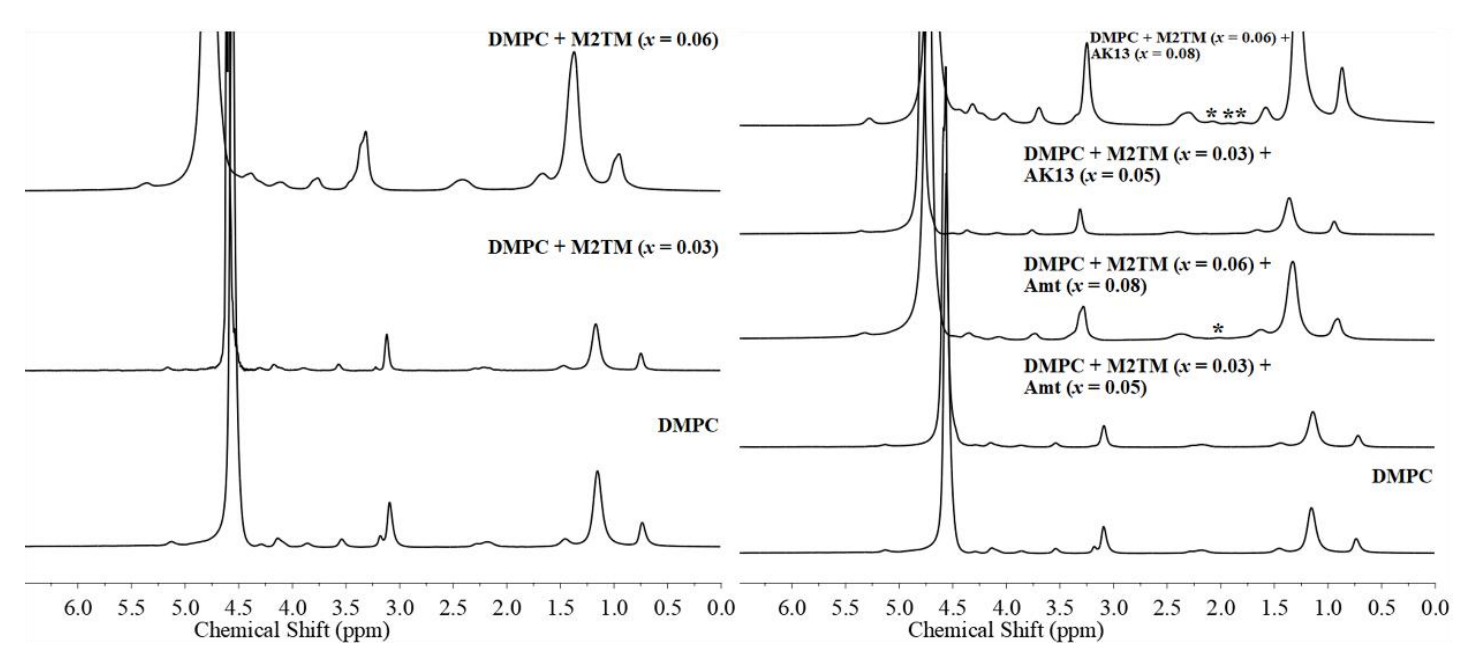

Figure 6. ${ }^{1} \mathrm{H}$ MAS NMR spectra of DMPC bilayers with M2TM (left) and with M2TM and Amt or AK13 (right) at $35^{\circ} \mathrm{C}$ and $\mathrm{pH} 8.0$.

${ }^{13} \mathrm{C} C P / M A S N M R$ at liquid crystalline phase: At $35^{\circ} \mathrm{C}$ and $\mathrm{pH} 8.0, \mathrm{M} 2 \mathrm{TM}$ at concentration $x=0.03$ did not modify chemical shifts and intensities of DMPC bilayers peaks and only at the higher concentration $x=0.06$ produced a change of the chemical shifts of DMPC bilayers at lower field (Table 8). These are identical effects as at $15^{\circ} \mathrm{C}$. Amt and $A K 13$ also caused in the gel phase temperature (Figure 7, Table 8).

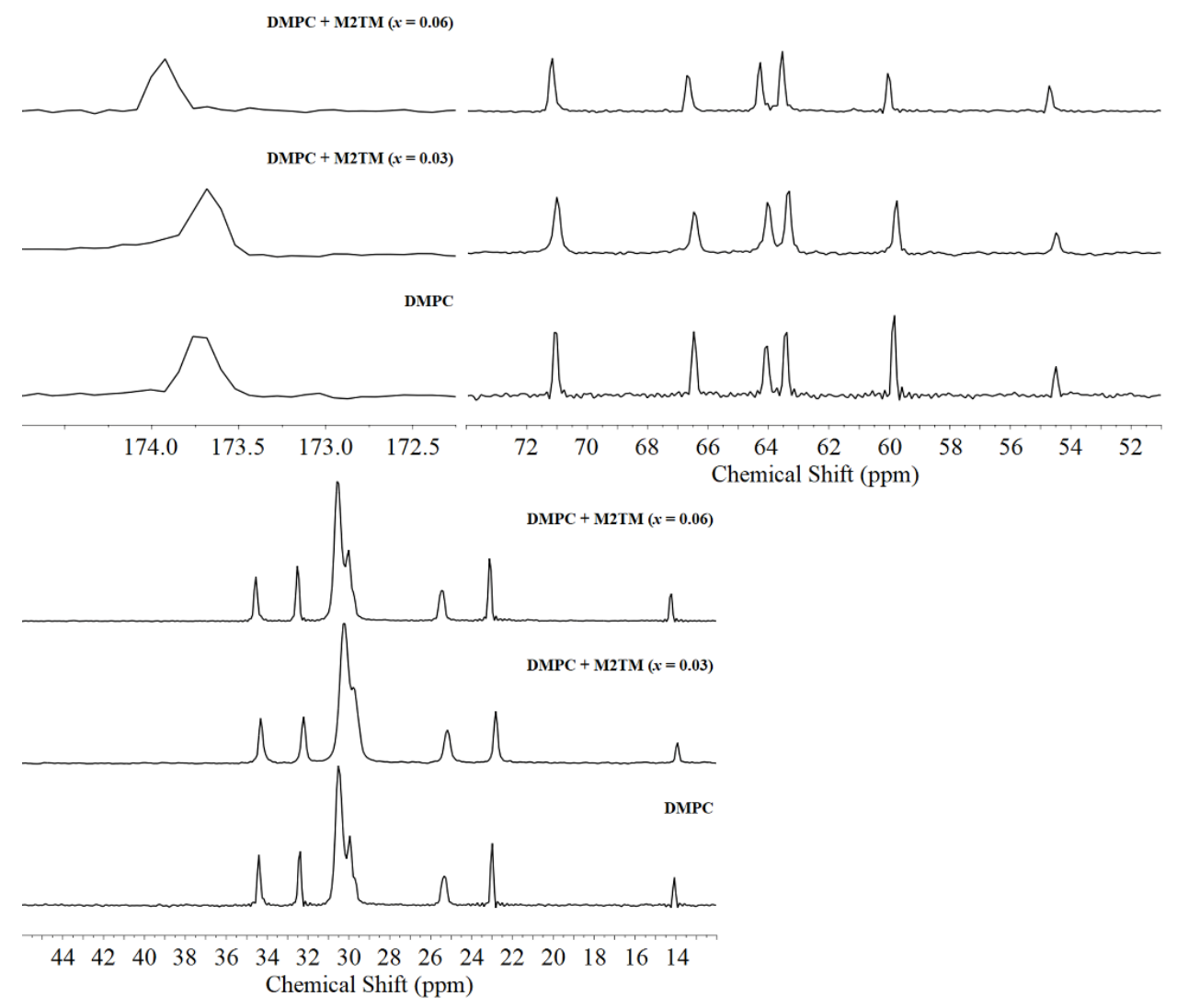




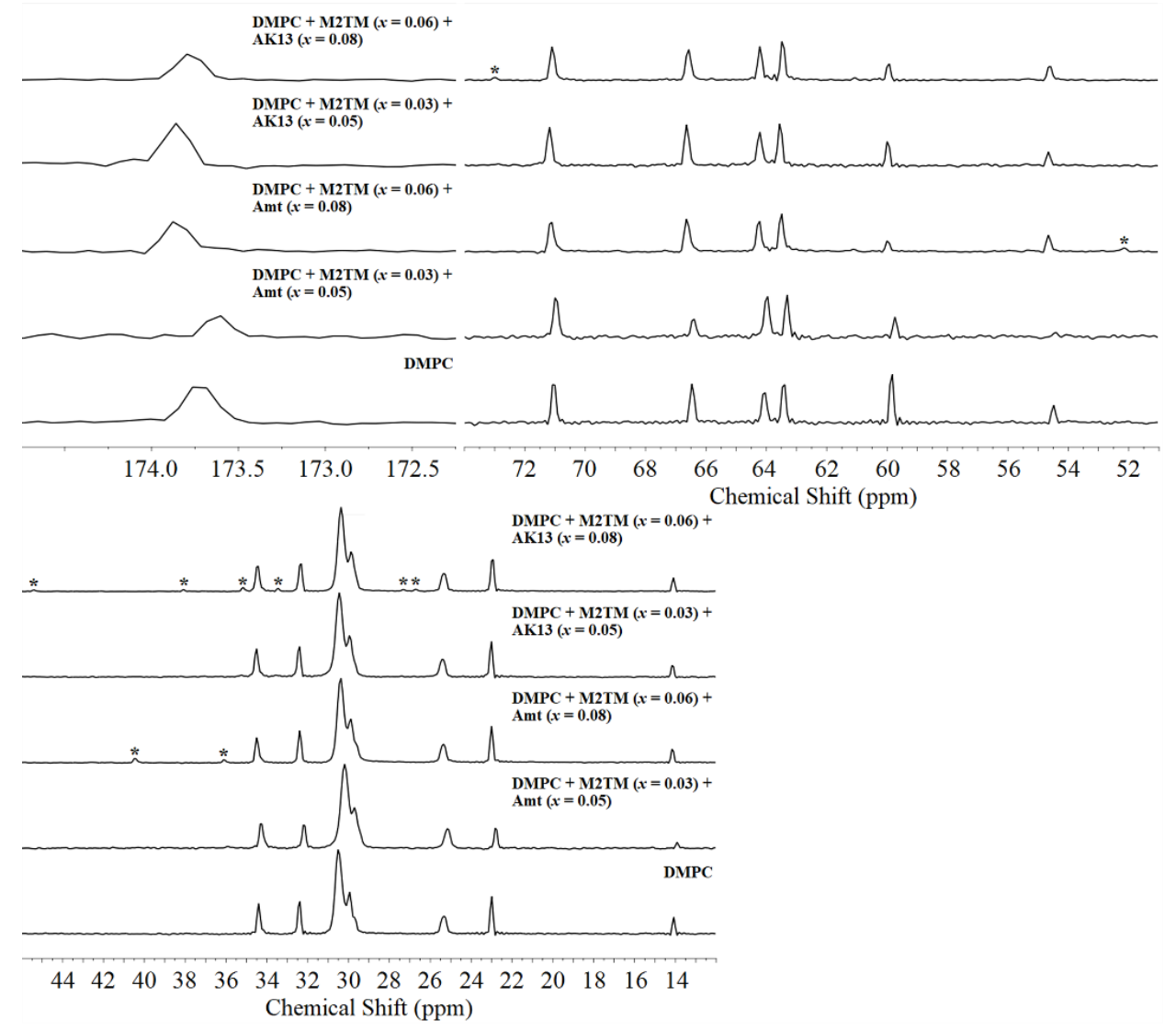

Figure 7. ${ }^{13} \mathrm{C}$ CP-MAS NMR spectra of DMPC bilayers with M2TM (upper traces) and with M2TM and Amt or AK13 (bottom traces) at $35^{\circ} \mathrm{C}$ and $\mathrm{pH} 8.0$.

${ }^{31} P$ NMR spectra in the liquid crystalline phase: Similar effects have been observed with ${ }^{31} \mathrm{P} N M R$ spectra in the liquid crystalline phase (Figure 8, Table 5). This is not surprising as also similar effects were observed in the ${ }^{1} \mathrm{H}$ and ${ }^{13} \mathrm{C}$ NMR spectra for the gel and liquid crystalline phase.

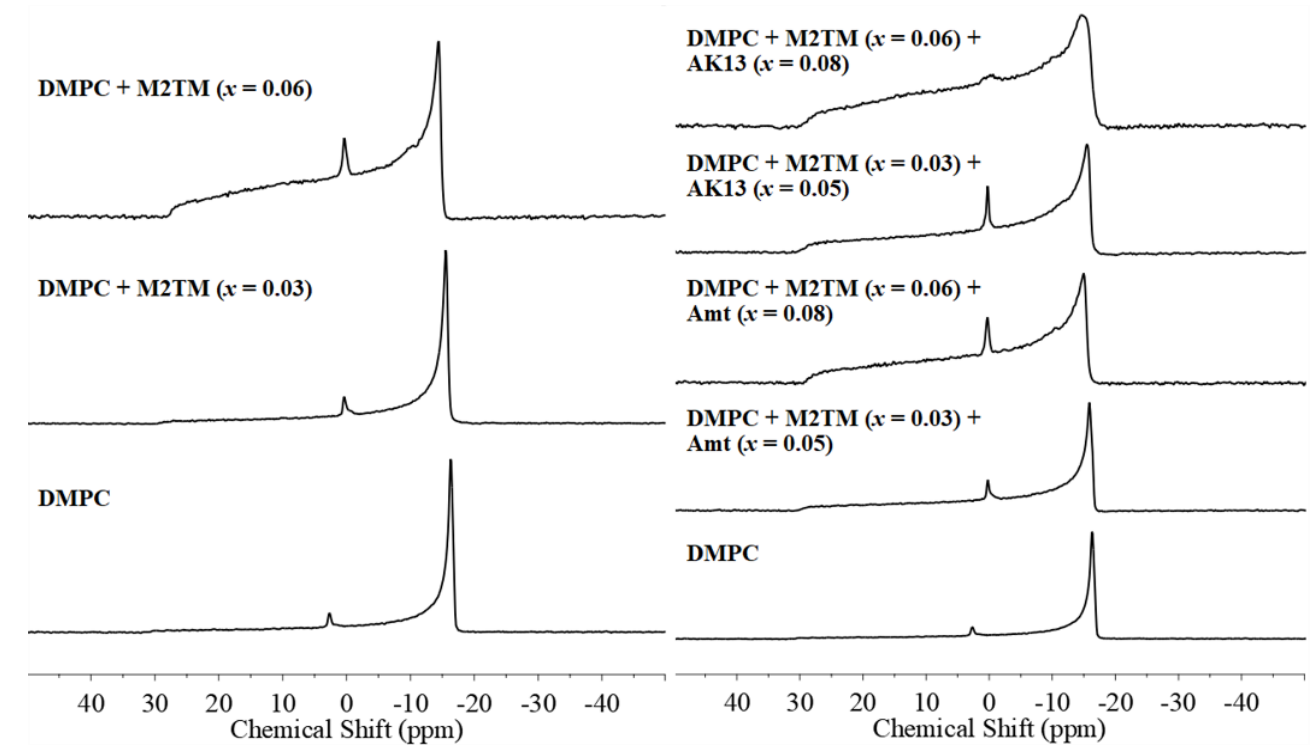

Figure 8. ${ }^{31} \mathrm{P}$ NMR spectra of DMPC bilayers with M2TM (left) and with M2TM and Amt or AK13 (right) at $35^{\circ} \mathrm{C}$ and $\mathrm{pH} 8.0$. 


\section{X-ray scattering}

X-ray scattering patterns of DMPC + M2TM $(x=0.03)$ in absence or presence of Amt or AK13 at concentration $x=0.05$ at $20^{\circ} \mathrm{C}$ (A) and $30^{\circ} \mathrm{C}$ (B) at $\mathrm{pH} 8.0$ are shown in Figure 9. The corresponding WAXS peaks arising from the lipids chain packing are shown in the insets.
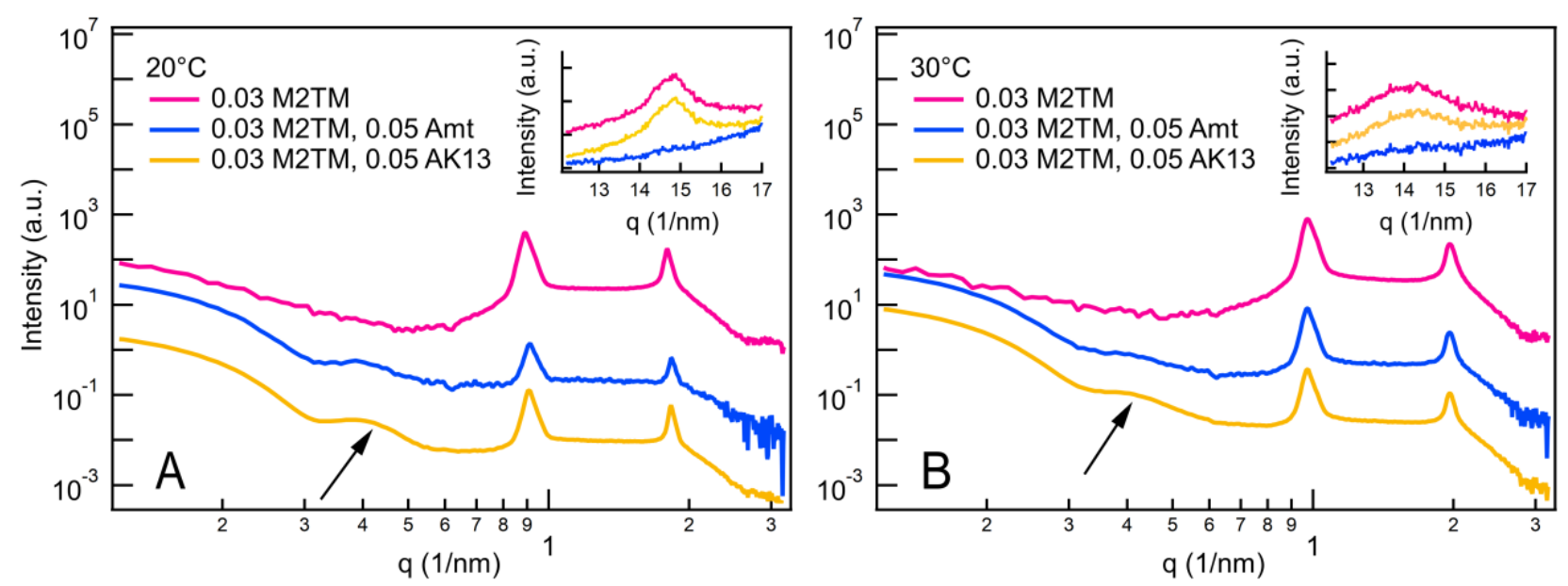

Figure 9. X-ray scattering curves of DMPC + M2TM $(x=0.03)$ in the absence or presence of Amt or AK13 at concentration $x=0.05$ at $20^{\circ} \mathrm{C}(A)$ and $30{ }^{\circ} \mathrm{C}(B)$ and at $\mathrm{pH}$ 8.0. Insets show the WAXS peak arising from the lipids chain packing. Traces were vertically shifted for clarity. The broad shoulder was indicated with an arrow.

At $20{ }^{\circ} \mathrm{C}$ a typical pattern of a bilayer was observed in DMPC + M2TM ( $\left.x=0.03\right)$. Adding the drug molecules, the formation of a broad shoulder was observed. This scattering pattern is consistent with DSC results suggesting the presence of two lipid domains, a major one with free lipids or free lipids including drugs molecules and a minor domain with M2TM boundary lipids. In the SAXS patterns drug molecules did not modify the d-spacing of DMPC + M2TM $(x=0.03)$ bilayers substantially (Table 9). However, in WAXS spectra Amt exerted a significant disordering of the chain packing, more so than $A K 13$, as no peak was evident at this temperature. At $30{ }^{\circ} \mathrm{C}$ the same conclusions can be drawn, implying that $A m t$ is acting more effectively in both mesomorphic states. The only difference is that, at liquid crystalline temperatures, Amt significantly expands the d-spacing of the lipid bilayers, i.e. to $69.16 \AA$ at $x=0.05$ (Table 9). The ordering of the bilayers (peak width) is unaffected by the change of temperature.

For high drug concentrations, i.e. DMPC+ M2TM $(x=0.06)$, $x$-ray scattering patterns in the absence or presence of $A m t$ or $A K 13(x=0.08)$ at $20^{\circ} \mathrm{C}(\mathrm{A})$ and $30^{\circ} \mathrm{C}(\mathrm{B})$, are shown in Figure 10. It is evident from the spectra at $20{ }^{\circ} \mathrm{C}$ that the broad component observed with lower peptide concentrations is absent. These results are again in harmony with DSC results showing the presence of only one lipid domain. Interestingly, in WAXS experiments all three samples at $20^{\circ} \mathrm{C}$ or at $30^{\circ} \mathrm{C}$ showed a very similar d-spacing which is again in consistent with the DSC results showing one domain of lipids uniformly occupied by M2TM and the Aamt ligand (Table 9). At both temperature the peak width of $A m t$ is larger than the others indicating the stronger activity for the side chain disorder. However, at $30{ }^{\circ} \mathrm{C}$, in the liquid crystalline phase the SAXS sample DMPC + M2TM $(x=0.06)+A m t(x=0.08)$ does not show any peaks i.e. the formation of unilamellar vesicles, indicating a drastic modification of the lamellar structure of the lipid bilayers. In contrast, DMPC + M2TM $(x=0.06)$ and DMPC + M2TM $(x=0.06)+A K 13(x=0.08)$ samples showed similar d-spacing results. This is again in agreement with DSC results in which at this concentration of the sample, Amt appears to cause the most significant effect. Highlighting further the discrepancy, as evidenced in ref. 29 using DMPC lipids with only Amt at the same concentration, more ordered bilayers were observed resulting in Bragg peaks in SAXS and WAXS experiments. In the present samples with one equivalent of M2TM tetramer, six equivalents of Amt drug and 120 or 60 lipid molecules, the excess of Aamt drug can form stronger ionic hydrogen bonding interactions through its ammonium group with lipid phosphate groups and M2TM D44 carboxylate groups close to the bilayer surface compared to $A K 13$ as discussed in the DSC results sub-section.

The activity of Amt is generally visible by comparing the WAXS peak data for all temperatures and concentrations (Tabel 9). Here the general trend is observable that higher drug concentrations (with the 
exception of $A m t$ ) cause increased side chain packing, which is evidenced by the smaller d-spacings and smaller peak widths in the WAXS regime.
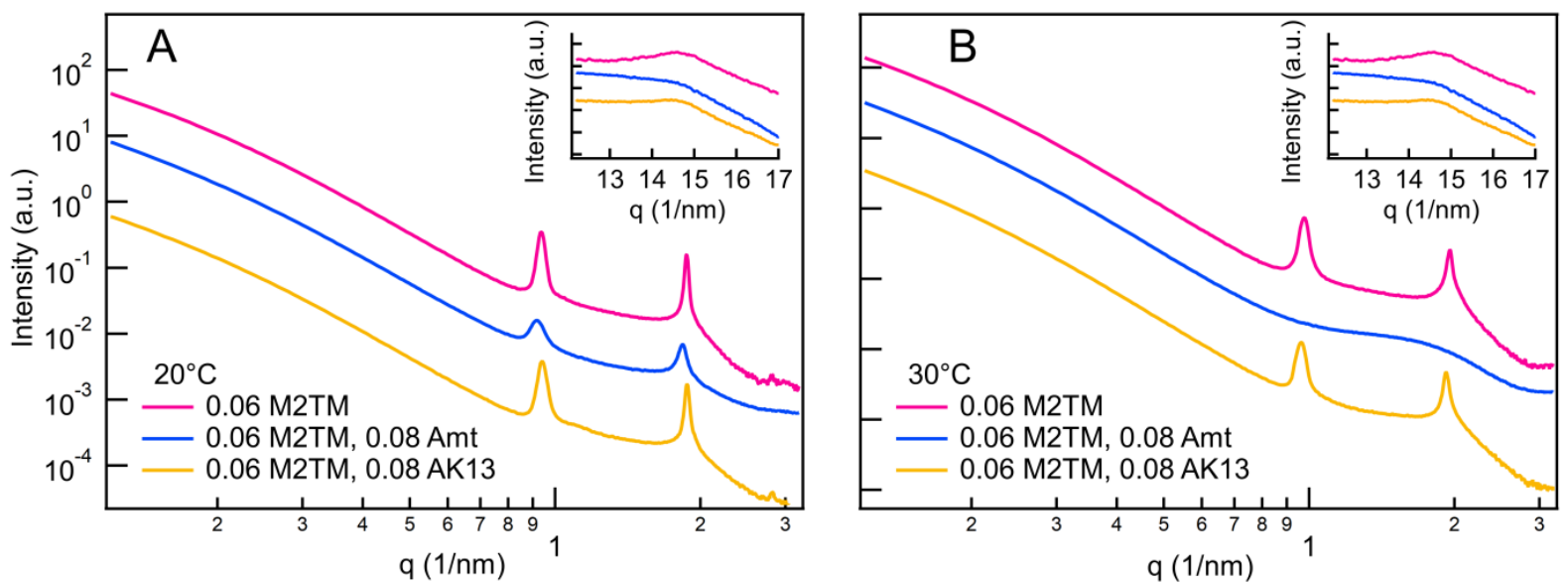

Figure 10. X-ray scattering curves of DMPC + M2TM $(x=0.06)$ in absence or presence of Amt or AK13 at high concentration $x=0.08,20^{\circ} \mathrm{C}(A)$ and $30{ }^{\circ} \mathrm{C}(B)$, and at $\mathrm{pH}$ 8.0. Insets show the WAXS peak arising from the lipids chain packing. Traces were vertically shifted for clarity.

\section{Simulations}

The MD simulations of the M2TM-Aamt complex and five molecules of Aamt in 120 DMPC lipids, to resemble experimental samples, showed that Aamt drug molecules were wrapped through ionic interactions to the lipid phosphate groups of the polar headgroup area and occasionally interact with M2TM D44 carboxylate groups lying close to the phosphate groups. This interaction was more frequent for AK13 compared to Amt. For the 120 DMPC lipids system the area-per-lipid for the M2TM boundary lipid region was calculated correspondingly at ca $47 \AA^{2}$; the definition of the boundary lipids was based on the Voronoi cells being close to the protein atoms. ${ }^{60}$ These values are significantly lower than the calculated area-perlipid for the bulk lipid domain being correspondingly at ca $63 \AA^{2}$. The M2TM boundary lipids are constricted because of their more oriented structure around M2TM. The experimental value for DMPC is ca $60 \AA^{2}$ as determined by SAXS. ${ }^{69}$ The measurement of the mean distance between unbound Aamt and the centroid of G34 showed that $A K 13$ remain closer to the M2TM compared to Amt, with the distance being $15 \AA$ compared to $25 \AA$. This preference of $A K 13$ to remain closer to M2TM may have important consequences leaving Amt to perturb more efficiently the DMPC bilayer. This is consistent with the RDF plots describing the distribution of an Aamt molecule from the center of the bilayer showing the frequent contact of AK13 while Amt was found apart from the M2TM pore (Figure S1).

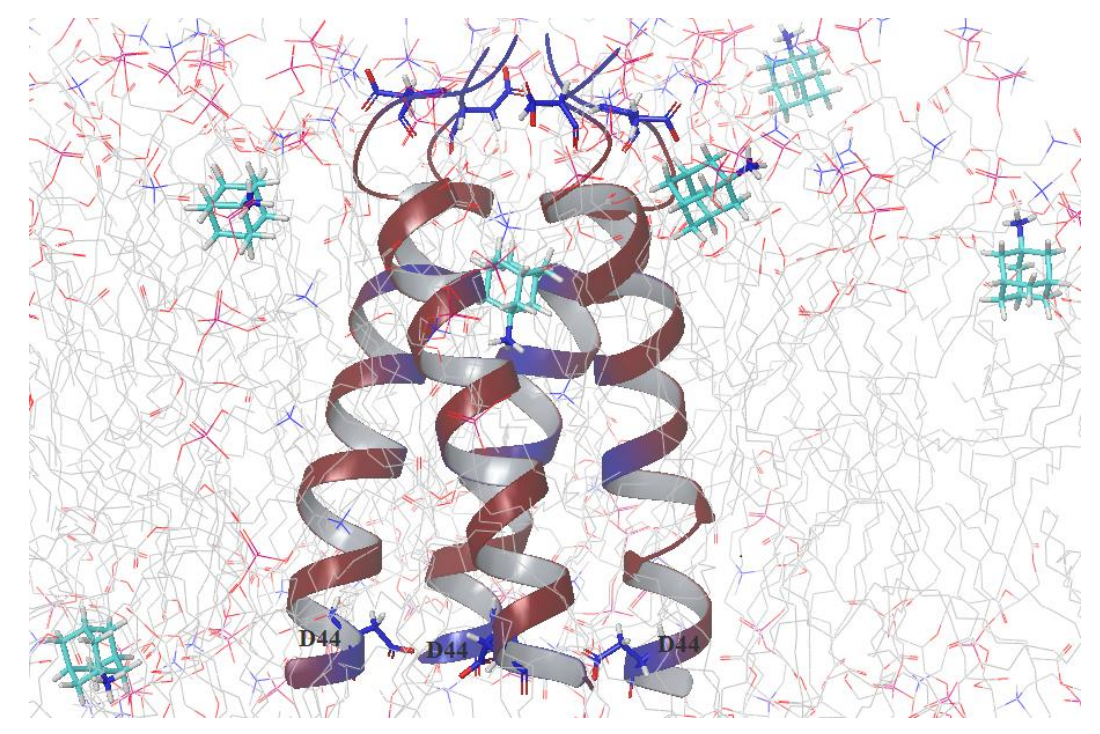




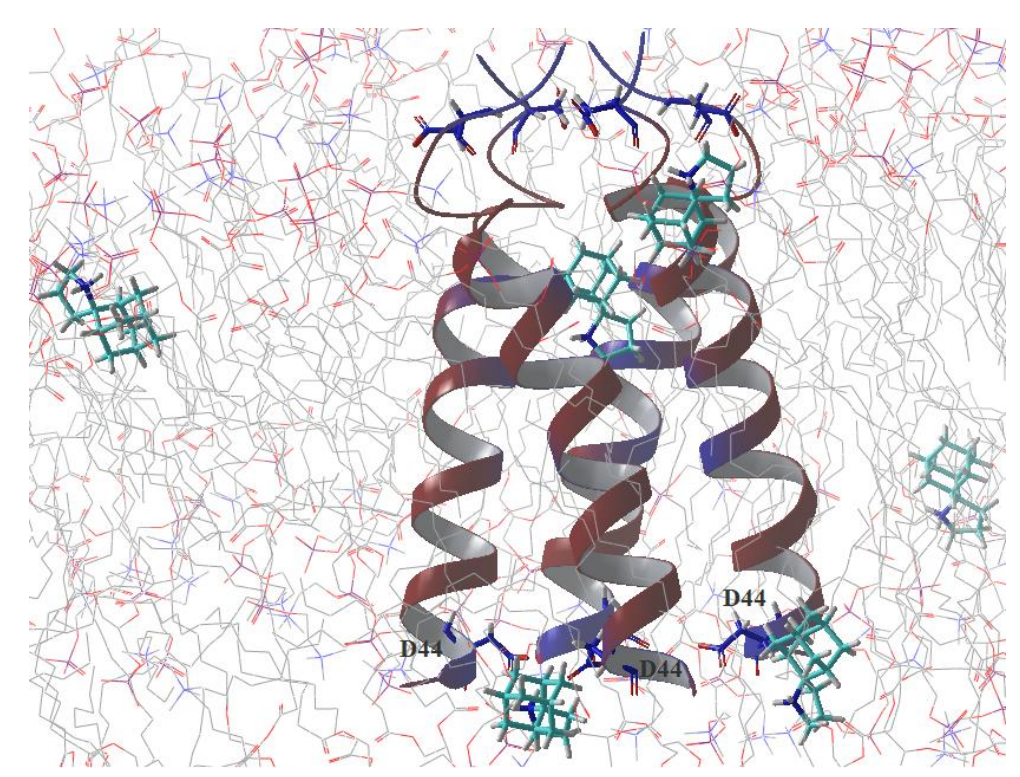

Figure 11. Screenshot from a $200 \mathrm{~ns}$ MD simulation of the system including: (top) the M2TM tetramer-Amt complex with five Amt molecules or (down) the M2TM tetramer-AK13 complex with five $A K 13$ molecules, in DMPC bilayers at $\mathrm{pH} 8.0$.

\section{Conclusions}

In the present study, the effect of $A m t$ and $A K 13$ to the DMPC bilayers containing the M2TM was studied. The comparative perturbation of $A m t$ and $A K 13$ to the DMPC bilayers has been previously investigated. ${ }^{29}$ In both studies a combination of experimental biophysical methods, ie DSC, SAXS/WAXS, ssNMR, and MD simulations were applied. It has been observed that both $A m t$ and $A K 13$ perturb similarly the DMPC bilayers in DSC, by decreasing $T_{m}$, broadening DMPC bilayers half-width, and increasing $\Delta H$ at low concentrations, ie when $x=0.05$. In addition, they abolished the pre-transition signifying a perturbing effect on the phosphate head-group or hydrocarbon chain tilts that prevents formation of the ripple phase. ${ }^{1} \mathrm{H},{ }^{13} \mathrm{C}$ and ${ }^{31} \mathrm{P}$ NMR experiments confirmed these results and provided additional molecular details, showing that the two molecules affect the glycerol backbone and the carbonyl region of the headgroup region in their amine form, or the phosphate groups in their ammonium form. M2TM in apo or Aamt-bound form span the membrane thickness and, according to ${ }^{31} \mathrm{P}$ ssNMR evidence, exerted strong interactions with phosphate groups of the polar head surface. In addition, the pre-transition seen in DSC is ablated by M2TM without drugs, indicating that, like the drugs, the high $(x=0.06,64$ lipid molecules per tetramer -32 in each leaflet $)$ and even the moderate $(x=0.03,120$ lipid molecules per tetramer -60 in each leaflet) peptide densities also perturb the headgroups or hydrocarbon chain tilts. The results of this work showed that at low concentration of embedded M2TM protein ( $x=0.03)$ in the DMPC bilayers in the absence or present of the Aamt drug $(x=0.05)$, the DSC scan revealed two domains, one of bound lipids around the apo form of the protein complex, and another of bulk-like domain. These findings were confirmed by SAXS experiments. This system became uniform when M2TM protein is increased in concentration in the bilayer $(x=0.06)$. The presence of an excess of the drugs as regards to M2TM in the membrane system affected the DSC profiles, indicating a clear perturbation in the M2TM containing bilayers. According to SAXS experiments, Amt induced a significant chain stacking disordering, in contrast to $A K 13$ which showed only milder effect. It is thus evident, that the membrane perturbing effects of these drugs are different in the system containing M2TM protein compared to the effects of these drugs alone. The changes in the shape of ${ }^{1} \mathrm{H}$ NMR ssNMR spectrum provide information about the fluidization of the bilayers and the changes in the chemical shifts of ${ }^{13} \mathrm{C}$ signals of the drug, which were clearly observed at concentration higher than $x=0.05$, suggested interactions of the drug with the bilayer system. The MD simulations showed that the excess drug molecules, not bound to the protein, anchored to the polar head region with their ammonium interacting with the lateral surfaces of M2TM and occasionally with its D44 carboxylate groups, the last interaction being more frequent for $A K 13$. The stronger effect of Amt compared to the more lipophilic $A K 13$ at low drug concentration, when $\mathrm{M} 2 \mathrm{TM}$ is present, is likely due to the to the preference of $A K 13$ to locate in closer vicinity to M2TM compared to Amt as well as the stronger ionic interactions of Amt primary ammonium group with phosphate groups, compared with the secondary buried ammonium group in $A K 13$. 


\section{Associated Content}

\section{Supporting Information}

Table S1. Sample preparation.

\section{Author Contribution}

AK design the project; AthK prepared the sample; AthK and TM performed the ssNMR experiments with the help of GM and TC, AthK and TM performed the x-ray experiments with the help of BS and HA; MC, NZ and CD performed the DSC experiments; MP, IT, TT synthesized and purified the M2TM peptide; all the authors provide detailed report and observations from their experiments; AthK, BS, HA and also MC, NZ improved considerably the figures from the results; AK interpreted the results with the help of TM, BS, HA, DB; TM and AK wrote the manuscript and BS, HZ and DB provided important revisions; all the authors accepted the manuscript.

\section{Notes}

The authors declare no competing financial interest

\section{Acknowledgements}

A.K. thanks Chiesi Hellas, which supported this research (SARG No 10354) and CERIC-ERIC Consortium for the access to experimental facilities and financial support (Proposal Numbers 20157043, 20167023 and 20172028). The MD simulations were run on the HPC infrastructure ARIS supercomputer using the CPU implementation codes of the Amber package.

\section{References}

1. Yang, N. J.; Hinner, M. J., Getting across the cell membrane: an overview for small molecules, peptides, and proteins. Methods Mol. Biol. 2015, 1266, 29-53.

2. Chizhmakov, I. V.; Geraghty, F. M.; Ogden, D. C.; Hayhurst, A.; Antoniou, M.; Hay, A. J., Selective proton permeability and $\mathrm{pH}$ regulation of the influenza virus $\mathrm{M} 2$ channel expressed in mouse erythroleukaemia cells. The Journal of Physiology 1996, 494 ( Pt 2) (Pt 2), 329-336.

3. Lin, T. I.; Schroeder, C., Definitive assignment of proton selectivity and attoampere unitary current to the M2 ion channel protein of influenza A virus. Journal of Virology 2001, 75 (8), 3647-3656.

4. Mould, J. A.; Drury, J. E.; Frings, S. M.; Kaupp, U. B.; Pekosz, A.; Lamb, R. A.; Pinto, L. H., Permeation and activation of the M2 ion channel of influenza A virus. J. Biol. Chem. 2000, 275 (40), 31038-31050.

5. Pinto, L. H.; Holsinger, L. J.; Lamb, R. A., Influenza virus M2 protein has ion channel activity. Cell 1992, 69 (3), 517-528.

6. Shimbo, K.; Brassard, D. L.; Lamb, R. A.; Pinto, L. H., Ion selectivity and activation of the M2 ion channel of influenza virus. Biophys. J. 1996, 70 (3), 1335-1346.

7. Cady, S. D.; Luo, W.; Hu, F.; Hong, M., Structure and function of the influenza A M2 proton channel. Biochemistry 2009, 48 (31), 7356-7364.

8. Ioannidis, H.; Drakopoulos, A.; Tzitzoglaki, C.; Homeyer, N.; Kolarov, F.; Gkeka, P.; Freudenberger, K.; Liolios, C.; Gauglitz, G.; Cournia, Z., et al., Alchemical Free Energy Calculations and Isothermal Titration Calorimetry Measurements of Aminoadamantanes Bound to the Closed State of Influenza A/M2TM. J. Chem. Inf. Model. 2016, 56 (5), 862-876.

9. Tzitzoglaki, C.; Wright, A.; Freudenberger, K.; Hoffmann, A.; Tietjen, I.; Stylianakis, I.; Kolarov, F.; Fedida, D.; Schmidtke, M.; Gauglitz, G., et al., Binding and Proton Blockage by Amantadine Variants of the Influenza M2WT and M2S31N Explained. J. Med. Chem. 2017, 60 (5), 1716-1733.

10. Ma, C.; Polishchuk, A. L.; Ohigashi, Y.; Stouffer, A. L.; Schon, A.; Magavern, E.; Jing, X.; Lear, J. D.; Freire, E.; Lamb, R. A., et al., Identification of the functional core of the influenza A virus A/M2 protonselective ion channel. Proc. Natl. Acad. Sci. U. S. A. 2009, 106 (30), 12283-12288.

11. Stouffer, A. L.; Acharya, R.; Salom, D.; Levine, A. S.; Di Costanzo, L.; Soto, C. S.; Tereshko, V.; Nanda, V.; Stayrook, S.; DeGrado, W. F., Structural basis for the function and inhibition of an influenza virus proton channel. Nature 2008, 451 (7178), 596-599. 
12. Thomaston, J. L.; Polizzi, N. F.; Konstantinidi, A.; Wang, J.; Kolocouris, A.; DeGrado, W. F., Inhibitors of the M2 Proton Channel Engage and Disrupt Transmembrane Networks of Hydrogen-Bonded Waters. J. Am. Chem. Soc. 2018, 140 (45), 15219-15226.

13. Hu, J.; Asbury, T.; Achuthan, S.; Li, C.; Bertram, R.; Quine, J. R.; Fu, R.; Cross, T. A., Backbone structure of the amantadine-blocked trans-membrane domain M2 proton channel from Influenza A virus. Biophys. J. 2007, 92 (12), 4335-4343.

14. Cady, S. D.; Schmidt-Rohr, K.; Wang, J.; Soto, C. S.; Degrado, W. F.; Hong, M., Structure of the amantadine binding site of influenza M2 proton channels in lipid bilayers. Nature 2010, 463 (7281), 689692.

15. Cady, S. D.; Wang, J.; Wu, Y.; DeGrado, W. F.; Hong, M., Specific binding of adamantane drugs and direction of their polar amines in the pore of the influenza M2 transmembrane domain in lipid bilayers and dodecylphosphocholine micelles determined by NMR spectroscopy. J. Am. Chem. Soc. 2011, 133 (12), 4274-4284.

16. Liossi, A. S.; Ntountaniotis, D.; Kellici, T. F.; Chatziathanasiadou, M. V.; Megariotis, G.; Mania, M.; Becker-Baldus, J.; Kriechbaum, M.; Krajnc, A.; Christodoulou, E., et al., Exploring the interactions of irbesartan and irbesartan-2-hydroxypropyl-beta-cyclodextrin complex with model membranes. Biochim. Biophys. Acta - Biomembranes 2017, 1859 (6), 1089-1098.

17. Sadeghpour, A.; Rappolt, M.; Ntountaniotis, D.; Chatzigeorgiou, P.; Viras, K.; Megariotis, G.; Papadopoulos, M. G.; Siapi, E.; Mali, G.; Mavromoustakos, T., Comparative study of interactions of aliskiren and AT1 receptor antagonists with lipid bilayers. Biochimica et biophysica acta 2015, 1848 (4), 984-994.

18. Markiewicz, B. N.; Lemmin, T.; Zhang, W.; Ahmed, I. A.; Jo, H.; Fiorin, G.; Troxler, T.; DeGrado, W. F.; Gai, F., Infrared and fluorescence assessment of the hydration status of the tryptophan gate in the influenza A M2 proton channel. Phys. Chem. Chem. Phys. 2016, 18 (41), 28939-28950.

19. Schmidt, N. W.; Mishra, A.; Wang, J.; DeGrado, W. F.; Wong, G. C., Influenza virus A M2 protein generates negative Gaussian membrane curvature necessary for budding and scission. J. Am. Chem. Soc. 2013, 135 (37), 13710-13719.

20. Hu, F.; Luo, W.; Cady, S. D.; Hong, M., Conformational plasticity of the influenza A M2 transmembrane helix in lipid bilayers under varying $\mathrm{pH}$, drug binding, and membrane thickness. Biochimica et biophysica acta 2011, 1808 (1), 415-423.

21. Cady, S.; Wang, T.; Hong, M., Membrane-dependent effects of a cytoplasmic helix on the structure and drug binding of the influenza virus M2 protein. J. Am. Chem. Soc. 2011, 133 (30), 11572-11579.

22. Saotome, K.; Duong-Ly, K. C.; Howard, K. P., Influenza A M2 protein conformation depends on choice of model membrane. Biopolymers 2015, 104 (4), 405-411.

23. Mandala, V. S.; Gelenter, M. D.; Hong, M., Transport-Relevant Protein Conformational Dynamics and Water Dynamics on Multiple Time Scales in an Archetypal Proton Channel: Insights from Solid-State NMR. J. Am. Chem. Soc. 2018, 140 (4), 1514-1524.

24. Qin, H.; Miao, Y.; Cross, T. A.; Fu, R., Beyond Structural Biology to Functional Biology: Solid-State NMR Experiments and Strategies for Understanding the M2 Proton Channel Conductance. J. Phys. Chem. B 2017, 121 (18), 4799-4809.

25. Cady, S. D.; Hong, M., Effects of amantadine on the dynamics of membrane-bound influenza A M2 transmembrane peptide studied by NMR relaxation. J. Biomol. NMR 2009, 45 (1-2), 185-196.

26. Cristian, L.; Lear, J. D.; DeGrado, W. F., Use of thiol-disulfide equilibria to measure the energetics of assembly of transmembrane helices in phospholipid bilayers. Proc. Natl. Acad. Sci. U. S. A. 2003, 100 (25), 14772-14777.

27. Wang, T.; Hong, M., Investigation of the curvature induction and membrane localization of the influenza virus M2 protein using static and off-magic-angle spinning solid-state nuclear magnetic resonance of oriented bicelles. Biochemistry 2015, 54 (13), 2214-2226.

28. Pan, J.; Dalzini, A.; Song, L., Cholesterol and phosphatidylethanolamine lipids exert opposite effects on membrane modulations caused by the M2 amphipathic helix. Biochim. Biophys. Acta - Biomembranes 2019, 1861 (1), 201-209.

29. Konstantinidi, A.; Naziris, N.; Chountoulesi, M.; Kiriakidi, S.; Sartori, B.; Kolokouris, D.; Amentisch, H.; Mali, G.; Ntountaniotis, D.; Demetzos, C., et al., Comparative Perturbation Effects Exerted by the Influenza A M2 WT Protein Inhibitors Amantadine and the Spiro[pyrrolidine-2,2'-adamantane] Variant AK13 to Membrane Bilayers Studied Using Biophysical Experiments and Molecular Dynamics Simulations. J. Phys. Chem. B 2018, 122 (43), 9877-9895. 
30. Wright, A. K.; Batsomboon, P.; Dai, J.; Hung, I.; Zhou, H. X.; Dudley, G. B.; Cross, T. A., Differential Binding of Rimantadine Enantiomers to Influenza A M2 Proton Channel. J. Am. Chem. Soc. 2016, 138 (5), 1506-1509.

31. Salom, D.; Hill, B. R.; Lear, J. D.; DeGrado, W. F., pH-dependent tetramerization and amantadine binding of the transmembrane helix of M2 from the influenza A virus. Biochemistry 2000, 39 (46), 14160-14170.

32. Kolocouris, N.; Foscolos, G. B.; Kolocouris, A.; Marakos, P.; Pouli, N.; Fytas, G.; Ikeda, S.; De Clercq, E., Synthesis and antiviral activity evaluation of some aminoadamantane derivatives. J. Med. Chem. 1994, 37, 2896-2902.

33. Tselios, T.; Probert, L.; Daliani, I.; Matsoukas, E.; Troganis, A.; Gerothanassis, I. P.; Mavromoustakos, T.; Moore, G. J.; Matsoukas, J. M., Design and synthesis of a potent cyclic analogue of the myelin basic protein epitope MBP72-85: importance of the Ala81 carboxyl group and of a cyclic conformation for induction of experimental allergic encephalomyelitis. J. Med. Chem. 1999, 42 (7), 1170-1177.

34. Ieronymaki, M.; Androutsou, M. E.; Pantelia, A.; Friligou, I.; Crisp, M.; High, K.; Penkman, K.; Gatos, D.; Tselios, T., Use of the 2-chlorotrityl chloride resin for microwave-assisted solid phase peptide synthesis. Biopolymers 2015, 104 (5), 506-514.

35. Tapeinou, A.; Matsoukas, M. T.; Simal, C.; Tselios, T., Review cyclic peptides on a merry-go-round; towards drug design. Biopolymers 2015, 104 (5), 453-461.

36. Emmanouil, M.; Tseveleki, V.; Triantafyllakou, I.; Nteli, A.; Tselios, T.; Probert, L., A Cyclic Altered Peptide Analogue Based on Myelin Basic Protein 87-99 Provides Lasting Prophylactic and Therapeutic Protection Against Acute Experimental Autoimmune Encephalomyelitis. Molecules 2018, 23 (2), 304.

37. Friligou, I.; Papadimitriou, E.; Gatos, D.; Matsoukas, J.; Tselios, T., Microwave-assisted solid-phase peptide synthesis of the 60-110 domain of human pleiotrophin on 2-chlorotrityl resin. J Amino Acids 2011, 40 (5), 1431-1440.

38. Kolocouris, A.; Zikos, C.; Broadhurst, R. W., 19F NMR detection of the complex between amantadine and the receptor portion of the influenza A M2 ion channel in DPC micelles. Bioorganic Med. Chem. Lett. 2007, 17 (14), 3947-3952.

39. Amenitsch, H.; Rappolt, M.; Kriechbaum, M.; Mio, H.; Laggner, P.; Bernstorff, S., First performance assessment of the small-angle X-ray scattering beamline at ELETTRA. J. Synchrotron Radiat. 1998, 5 (Pt 3), 506-508.

40. Hammersley, A. P. ESRF97HA02T, “FIT2D: An introduction and overview"; 1997.

41. Zhang, R.; Tristram-Nagle, S.; Sun, W.; Headrick, R. L.; Irving, T. C.; Suter, R. M.; Nagle, J. F., Smallangle $\mathrm{x}$-ray scattering from lipid bilayers is well described by modified Caillé theory but not by paracrystalline theory. Biophys. J. 1996, 70 (1), 349-357.

42. Rappolt, M., Bilayer thickness estimations with "poor" diffraction data. J. Appl. Phys. 2010, 107 (8), 084701.

43. Cady, S.; Wang, T.; Hong, M., Membrane-dependent effects of a cytoplasmic helix on the structure and drug binding of the influenza virus M2 protein. Journal of the American Chemical Society 2011, 133 (30), 11572-11579.

44. Jorgensen, W. L.; Chandrasekhar, J.; Madura, J. D.; Impey, R. W.; Klein, M. L., Comparison of simple potential functions for simulating liquid water. J. Chem. Phys. 1983, 79 (2), 926-935.

45. Bowers, K. J.; Chow, E.; Xu, H.; Dror, R. O.; Eastwood, M. P.; Gregersen, B. A.; Klepeis, J. L.; Kolossvary, I.; Moraes, M. A.; Sacerdoti, F. D., et al., Scalable algorithms for molecular dynamics simulations on commodity clusters. In Proceedings of the 2006 ACM/IEEE conference on Supercomputing, ACM: Tampa, Florida, 2006; p 84.

46. Schrodinger, L., Maestro-Desmond Interoperability Tools, version 3.1. 2012.

47. Jorgensen, W. L.; Maxwell, D. S.; Tirado-Rives, J., Development and Testing of the OPLS All-Atom Force Field on Conformational Energetics and Properties of Organic Liquids. J. Am. Chem. Soc. 1996, 118 (45), 11225-11236.

48. Kaminski, G. A.; Friesner, R. A.; Tirado-Rives, J.; Jorgensen, W. L., Evaluation and Reparametrization of the OPLS-AA Force Field for Proteins via Comparison with Accurate Quantum Chemical Calculations on Peptides. The Journal of Physical Chemistry B 2001, 105 (28), 6474-6487.

49. Rizzo, R. C.; Jorgensen, W. L., OPLS All-Atom Model for Amines: Resolution of the Amine Hydration Problem. Journal of the American Chemical Society 1999, 121 (20), 4827-4836.

50. Hornak, V.; Abel, R.; Okur, A.; Strockbine, B.; Roitberg, A.; Simmerling, C., Comparison of multiple Amber force fields and development of improved protein backbone parameters. Proteins 2006, 65 (3), 712-725. 
51. Essmann, U.; Perera, L.; Berkowitz, M. L.; Darden, T.; Lee, H.; Pedersen, L. G., A smooth particle mesh Ewald method. J. Chem. Phys. 1995, 103 (19), 8577-8593.

52. Darden, T.; York, D.; Pedersen, L., Particle mesh Ewald: An $\mathrm{N} \cdot \log (\mathrm{N})$ method for Ewald sums in large systems. J. Chem. Phys. 1993, 98 (12), 10089-10092.

53. Martyna, G. J.; Tobias, D. J.; Klein, M. L., Constant pressure molecular dynamics algorithms. J. Chem. Phys. 1994, 101 (5), 4177-4189.

54. Humphreys, D. D.; Friesner, R. A.; Berne, B. J., A Multiple-Time-Step Molecular Dynamics Algorithm for Macromolecules. The Journal of Physical Chemistry 1994, 98 (27), 6885-6892.

55. Koynova, R.; Caffrey, M., Phases and phase transitions of the phosphatidylcholines. Biochimica et Biophysica Acta (BBA) - Reviews on Biomembranes 1998, 1376 (1), 91-145.

56. Humphrey, W.; Dalke, A.; Schulten, K., VMD: Visual molecular dynamics. Journal of Molecular Graphics 1996, 14 (1), 33-38.

57. Schrodinger, L., Maestro, version 8.5. 2008.

58. Berendsen, H. J. C.; van der Spoel, D.; van Drunen, R., GROMACS: A message-passing parallel molecular dynamics implementation. Computer Physics Communications 1995, 91 (1), 43-56.

59. Hess, B.; Kutzner, C.; van der Spoel, D.; Lindahl, E., GROMACS 4: Algorithms for Highly Efficient, Load-Balanced, and Scalable Molecular Simulation. Journal of Chemical Theory and Computation 2008, $4(3), 435-447$.

60. Mori, T.; Ogushi, F.; Sugita, Y., Analysis of lipid surface area in protein-membrane systems combining Voronoi tessellation and Monte Carlo integration methods. J. Comput. Chem. 2012, 33 (3), 286-293.

61. Koynova, R.; Caffrey, M., Phases and phase transitions of the phosphatidylcholines. Biochimica et biophysica acta 1998, 1376 (1), 91-145.

62. Heimburg, T., A model for the lipid pretransition: coupling of ripple formation with the chain-melting transition. Biophys. J. 2000, 78 (3), 1154-1165.

63. Posch, M.; Rakusch, U.; Mollay, C.; Laggner, P., Cooperative Effects in the Interaction between Melittin and Phosphatidylcholine Model Membranes - Studies by Temperature Scanning Densitometry. J. Biol. Chem. 1983, 258 (3), 1761-1766.

64. Lohner, K.; Latal, A.; Lehrer, R. I.; Ganz, T., Differential scanning microcalorimetry indicates that human defensin, HNP-2, interacts specifically with biomembrane mimetic systems. Biochemistry 1997, $36(6), 1525-1531$.

65. Chiu, M. H.; Prenner, E. J., Differential scanning calorimetry: An invaluable tool for a detailed thermodynamic characterization of macromolecules and their interactions. J. Pharm. Bioallied Sci. 2011, $3(1), 39-59$.

66. Intharathep, P.; Rungrotmongkol, T.; Decha, P.; Nunthaboot, N.; Kaiyawet, N.; Kerdcharoen, T.; Sompornpisut, P.; Hannongbua, S., Evaluating how rimantadines control the proton gating of the influenza A M2-proton port via allosteric binding outside of the M2-channel: MD simulations. J. Enzyme Inhib. Med. Chem. 2011, 26 (2), 162-168.

67. Nomura, K.; Lintuluoto, M.; Morigaki, K., Hydration and temperature dependence of 13C and 1H NMR spectra of the DMPC phospholipid membrane and complete resonance assignment of its crystalline state. J. Phys. Chem. B 2011, 115 (50), 14991-15001.

68. Liao, S. Y.; Lee, M.; Hong, M., Interplay between membrane curvature and protein conformational equilibrium investigated by solid-state NMR. J. Struct. Biol. 2018.

69. Balgavý, P.; Dubničková, M.; Kučerka, N.; Kiselev, M. A.; Yaradaikin, S. P.; Uhríková, D., Bilayer thickness and lipid interface area in unilamellar extruded 1,2-diacylphosphatidylcholine liposomes: a small-angle neutron scattering study. Biochim. Biophys. Acta-Biomembranes 2001, 1512 (1), 40-52. 
Table 1. Calorimetric heating profiles of DMPC + M2TM without or with Amt or AK13. The DMPC bilayers were fully hydrated in phosphate buffer at $\mathrm{pH} 8.0$

\begin{tabular}{|c|c|c|c|c|c|c|c|c|}
\hline Sample & $\begin{array}{c}T_{\text {onset,m }} \\
\left({ }^{\circ} \mathbf{C}\right)\end{array}$ & $\begin{array}{l}T_{\mathbf{m}} \\
\left({ }^{\circ} \mathbf{C}\right)\end{array}$ & $\begin{array}{l}\Delta T_{1 / 2, \mathrm{~m}} \\
\left({ }^{\circ} \mathrm{C}\right)\end{array}$ & $\begin{array}{c}\Delta H_{\mathrm{m}} \\
\left(\mathrm{kJ} \mathrm{mol}^{-1}\right)\end{array}$ & $\begin{array}{c}T_{\text {onset, }} \\
\left({ }^{\circ} \mathbf{C}\right)\end{array}$ & $\begin{array}{c}T_{\mathbf{s}} \\
\left({ }^{\circ} \mathbf{C}\right)\end{array}$ & $\begin{array}{l}\Delta T_{1 / 2, \mathrm{~s}} \\
\left({ }^{\circ} \mathbf{C}\right)\end{array}$ & $\begin{array}{c}\Delta H_{\mathrm{s}} \\
\left(\mathrm{kJ} \mathrm{mol}^{-1}\right)\end{array}$ \\
\hline DMPC & 23.07 & 23.43 & 0.71 & 29.44 & 12.32 & 13.27 & 1.14 & 3.11 \\
\hline$D M P C+M 2 T M(x=0.03)$ & 16.76 & 20.60 & 5.56 & 19.81 & - & - & - & - \\
\hline $\begin{array}{c}D M P C+M 2 T M(x=0.03) \\
+\operatorname{Amt}(x=0.05)\end{array}$ & 16.17 & 18.91 & 2.73 & 19.79 & - & - & - & - \\
\hline $\begin{array}{c}D M P C+M 2 T M(x=0.03) \\
+A K 13(x=0.05)\end{array}$ & 15.40 & 18.37 & 2.99 & 19.44 & - & - & - & - \\
\hline$D M P C+M 2 T M(x=0.06)$ & 16.94 & 22.77 & 6.20 & 11.23 & - & - & - & - \\
\hline $\begin{array}{c}\text { DMPC }+ \text { M2TM }(x=0.06) \\
+\operatorname{Amt}(x=0.08)\end{array}$ & 11.07 & 15.88 & 9.23 & 14.36 & - & - & - & - \\
\hline $\begin{array}{c}D M P C+M 2 T M(x=0.06) \\
+A K 13(x=0.08)\end{array}$ & 14.78 & 21.34 & 6.37 & 10.24 & - & - & - & - \\
\hline
\end{tabular}

$T_{\text {onset }}$ : temperature at which the thermal event starts; $T$ : temperature at which heat capacity $\Delta C_{\mathrm{p}}$ at constant pressure is maximum; $\Delta T_{1 / 2}$ : half width at half peak height of the transition; $\Delta H$ : transition enthalpy normalized per mol of lipid. Subscript m: main transition; subscript s: secondary transition (i.e. pretransition).

Table 2. Chemical shifts observed in ${ }^{1} \mathrm{H}$ MAS NMR spectra of DMPC bilayers with and without the Amt or $A K 13$ at $\mathrm{pH} 8.0$ and at $15^{\circ} \mathrm{C}$.

\begin{tabular}{|c|c|c|c|c|c|c|}
\hline Sample & H3 & $\begin{array}{l}\mathbf{H}\left(4^{\prime}-13^{\prime}\right), \\
\mathbf{H}\left(4^{\prime \prime}-13^{\prime \prime}\right)\end{array}$ & $\begin{array}{l}\text { H14', } \\
\text { H14" }\end{array}$ & $\mathbf{N}\left(\mathrm{CH}_{3}\right)_{3}$ & H2'"' & H1"' \\
\hline DMPC & & & & $2.6-3.3$ & 3.6 & 4.2 \\
\hline$D M P C+M 2 T M(x=0.03)$ & & 1.2 & 0.7 & $2.7-3.4$ & 3.6 & 4.2 \\
\hline$D M P C+M 2 T M(x=0.06)$ & 4.4 & $0.1-2.7$ & $0.1-2.7$ & 3.3 & 3.8 & \\
\hline $\begin{array}{c}D M P C+M 2 T M(x=0.03) \\
+\operatorname{Amt}(x=0.05)\end{array}$ & & $0.1-2.3$ & $0.1-2.3$ & 3.1 & 3.5 & 4.1 \\
\hline $\begin{array}{c}D M P C+M 2 T M(x=0.06) \\
+A m t(x=0.08)\end{array}$ & 4.4 & 1.3 & 0.9 & 3.3 & 3.7 & \\
\hline $\begin{array}{c}D M P C+M 2 T M(x=0.03) \\
+A K 13(x=0.05)\end{array}$ & & $0.1-2.8$ & $0.1-2.8$ & 3.3 & 3.8 & 4.4 \\
\hline $\begin{array}{c}D M P C+M 2 T M(x=0.06) \\
+A K 13(x=0.08)\end{array}$ & 4.3 & 1.3 & 0.9 & 3.3 & 3.7 & \\
\hline
\end{tabular}

Table 3. Chemical shifts observed in ${ }^{13} \mathrm{C}$ CP-MAS NMR spectra of DMPC bilayers with and without Amt or $A K 13$ at $15{ }^{\circ} \mathrm{C}$ and $\mathrm{pH} 8.0$.

\begin{tabular}{|c|c|c|c|c|c|c|c|c|c|c|c|c|c|}
\hline Sample & C1 & $\mathrm{C2}$ & $\mathbf{C 3}$ & $\begin{array}{l}\text { C1', } \\
\text { C1" }\end{array}$ & $\begin{array}{l}\text { C2', } \\
\text { C2" }\end{array}$ & $\begin{array}{l}\text { C3', } \\
\text { C3" }\end{array}$ & $\begin{array}{l}\text { C(4'-11'), } \\
\text { C(4'-11') }\end{array}$ & $\begin{array}{l}\text { C12', } \\
\text { C12" }\end{array}$ & $\begin{array}{l}\text { C13', } \\
\text { C13" }\end{array}$ & $\begin{array}{l}\text { C14', } \\
\text { C14" }\end{array}$ & $\mathbf{N}\left(\mathrm{CH}_{3}\right)_{3}$ & C2"' & C1"' \\
\hline DMPC & 63.3 & 70.9 & 64.0 & 173.6 & 34.3 & 25.2 & $29.0-31.3$ & 32.3 & 22.9 & 14.0 & 54.4 & 66.3 & 59.7 \\
\hline$D M P C+M 2 T M(x=0.03)$ & 63.3 & 70.9 & 64.0 & 173.7 & 34.3 & 25.2 & $28.8-31.7$ & 32.3 & 22.9 & 14.0 & 54.4 & 66.4 & 59.8 \\
\hline$D M P C+M 2 T M(x=0.06)$ & 63.5 & 71.1 & 64.3 & 173.9 & 34.6 & 25.6 & 29.4-32.3 & 32.7 & 23.3 & 14.4 & 54.6 & 66.5 & 60.1 \\
\hline $\begin{array}{c}\text { DMPC }+\operatorname{M2TM}(x=0.03) \\
+\operatorname{Amt}(x=0.05)\end{array}$ & 63.3 & 70.9 & 64.0 & 173.6 & 34.3 & 25.2 & $29.2-31.8$ & 32.2 & 22.8 & 13.9 & 54.4 & 66.4 & 59.8 \\
\hline $\begin{array}{c}D M P C+\operatorname{M2TM}(x=0.06) \\
+\operatorname{Amt}(x=0.08)\end{array}$ & 63.5 & 71.0 & 64.2 & 173.9 & 34.5 & 25.5 & $29.6-31.7$ & 32.5 & 23.1 & 14.2 & 54.5 & 66.5 & 60.0 \\
\hline $\begin{array}{c}D M P C+M 2 T M(x=0.03) \\
+A K 13(x=0.05)\end{array}$ & 63.6 & 71.2 & 64.2 & 173.9 & 34.5 & 25.4 & $29.2-31.8$ & 32.5 & 23.1 & 14.2 & 54.7 & 66.6 & 60.0 \\
\hline $\begin{array}{c}D M P C+M 2 T M(x=0.06) \\
+A K 13(x=0.08)\end{array}$ & 63.4 & 71.0 & 64.2 & 173.8 & 34.5 & 25.4 & $28.7-31.7$ & 32.5 & 23.1 & 14.2 & 54.5 & 66.5 & 60.0 \\
\hline
\end{tabular}

Table 4. Chemical shifts of $A m t$ and $A K 13$ observed in ${ }^{13} \mathrm{C}$ NMR high-resolution spectra at $15{ }^{\circ} \mathrm{C}$ and $35{ }^{\circ} \mathrm{C}$ and $\mathrm{pH}$ 8.0.

\begin{tabular}{|l|l|l|l|l|} 
Sample & ${ }^{13} \mathrm{C}$ NMR & Identification & $15^{\circ} \mathrm{C}$ & $35^{\circ} \mathrm{C}$ \\
\hline
\end{tabular}




\begin{tabular}{|c|c|c|c|c|}
\hline & $\begin{array}{c}\text { of } A m t \\
\text { and } A K 13 \\
\text { salts in } \\
\mathrm{D}_{2} \mathrm{O}\end{array}$ & & $\begin{array}{c}{ }^{13} \text { C-CP } \\
\text { MAS } \\
\text { NMR }\end{array}$ & $\begin{array}{c}{ }^{13} \mathrm{C}-\mathrm{CP} \\
\text { MAS } \\
\text { NMR }\end{array}$ \\
\hline$D M P C+M 2 T M(x=0.03)$ & - & - & - & - \\
\hline$D M P C+M 2 T M(x=0.06)$ & - & - & - & - \\
\hline $\begin{array}{c}D M P C+\operatorname{M2TM}(x=0.03) \\
+\operatorname{Amt}(x=0.05)\end{array}$ & $\begin{array}{l}52.9 \\
40.0 \\
34.8 \\
28.7 \\
\end{array}$ & $\begin{array}{c}\text { 1' } \\
\text { 2', 8', } 9 \\
\text { 4', 6', 10' } \\
\text { 3', 5', 7' }\end{array}$ & 35.9 & 35.9 \\
\hline $\begin{array}{c}D M P C+M 2 T M(x=0.06) \\
+\operatorname{Amt}(x=0.08)\end{array}$ & $\begin{array}{l}52.9 \\
40.0 \\
34.8 \\
28.7 \\
\end{array}$ & $\begin{array}{c}\text { 1', } \\
\text { 2', 8',9 } \\
\text { 4',6', 10' } \\
\text { 3', 5', 7' }\end{array}$ & $\begin{array}{l}52.0 \\
40.4 \\
36.1 \\
29.5 \\
\end{array}$ & $\begin{array}{l}52.2 \\
40.5 \\
36.1\end{array}$ \\
\hline $\begin{array}{c}D M P C+M 2 T M(x=0.03) \\
+A K 13(x=0.05)\end{array}$ & $\begin{array}{l}73.9 \\
44.6 \\
36.7 \\
34.3 \\
34.2 \\
34.0 \\
32.8 \\
26.1 \\
25.9 \\
22.6 \\
\end{array}$ & $\begin{array}{c}2 ' \\
5 \\
6 ' \\
1 ', 3, \\
3 \\
8,, 10^{\prime} \\
4 ', 9 \\
5, \\
7 \\
4\end{array}$ & $\begin{array}{l}35.3 \\
33.6 \\
27.5 \\
26.8\end{array}$ & $\begin{array}{l}35.2 \\
33.6\end{array}$ \\
\hline $\begin{array}{c}D M P C+M 2 T M(x=0.06) \\
+A K 13(x=0.08)\end{array}$ & $\begin{array}{l}73.9 \\
44.6 \\
36.7 \\
34.3 \\
34.2 \\
34.0 \\
32.8 \\
26.1 \\
25.9 \\
22.6 \\
\end{array}$ & $\begin{array}{c}2 \\
5 \\
6, \\
1,, 3, \\
3 \\
8^{\prime}, 10 \\
4 ', 9 \\
5, \\
7, \\
4 \\
\end{array}$ & $\begin{array}{c}72.9,63.7 \\
45.4 \\
38.1 \\
35.2\end{array}$ & $\begin{array}{l}35.2 \\
33.5 \\
27.3 \\
26.7\end{array}$ \\
\hline
\end{tabular}

Table 5. Components of the ${ }^{31} \mathrm{P}$ chemical shielding tensors of DMPC bilayers without and with Amt or AK13 at 15 or $35^{\circ} \mathrm{C}$ and $\mathrm{pH} 8.0$.

\begin{tabular}{|c|c|c|}
\hline \multirow[t]{2}{*}{ Sample } & \multicolumn{2}{|c|}{$\sigma_{I I}-\sigma_{I}$} \\
\hline & $15^{\circ} \mathrm{C}$ & $35^{\circ} \mathrm{C}$ \\
\hline DMPC & 55.5 & 48.5 \\
\hline$D M P C+M 2 T M(x=0.03)$ & 45.7 & 45.6 \\
\hline$D M P C+M 2 T M(x=0.06)$ & 41.7 & 42.7 \\
\hline $\begin{array}{c}D M P C+M 2 T M(x=0.03) \\
+A m t(x=0.05)\end{array}$ & 46.0 & 46.8 \\
\hline $\begin{array}{c}D M P C+M 2 T M(x=0.06) \\
+A m t(x=0.08)\end{array}$ & 44.6 & 44.9 \\
\hline $\begin{array}{c}D M P C+M 2 T M(x=0.03) \\
+A K 13(x=0.05)\end{array}$ & 45.4 & 46.3 \\
\hline $\begin{array}{c}D M P C+M 2 T M(x=0.06) \\
+A K 13(x=0.08)\end{array}$ & 44.8 & 45.1 \\
\hline
\end{tabular}

Table 6. Chemical shifts observed in ${ }^{1} \mathrm{H}$ MAS NMR spectra of DMPC bilayers without and with Amt or $A K 13$ at $35^{\circ} \mathrm{C}$ and $\mathrm{pH} 8.0$.

\begin{tabular}{|c|c|c|c|c|c|c|c|c|c|c|}
\hline Sample & H1 & H2 & H3 & $\begin{array}{c}\text { H2', } \\
\text { H2' }\end{array}$ & $\begin{array}{c}\text { H3', } \\
\text { H3' }\end{array}$ & $\begin{array}{c}\text { H(4'-13'), } \\
\text { H(4'-13') }\end{array}$ & $\begin{array}{l}\text { H14', } \\
\text { H14' }\end{array}$ & N(CH (C) $^{\prime \prime}$ & H2'"' & H1'"' \\
\hline
\end{tabular}




\begin{tabular}{|c|c|c|c|c|c|c|c|c|c|c|}
\hline DMPC & 3.9 & 5.1 & 4.3 & $2.0-2.4$ & 1.5 & 1.2 & 0.7 & $2.9-3.3$ & 3.5 & 4.1 \\
\hline$D M P C+M 2 T M(x=0.03)$ & 3.9 & 5.2 & 4.3 & $2.1-2.4$ & 1.5 & 1.2 & 0.8 & $3.0-3.3$ & 3.6 & 4.2 \\
\hline$D M P C+M 2 T M(x=0.06)$ & 4.1 & 5.4 & 4.4 & 2.4 & 1.7 & 1.4 & 1.0 & 3.3 & 3.8 & 4.4 \\
\hline $\begin{array}{c}D M P C+M 2 T M(x=0.03) \\
+A m t(x=0.05)\end{array}$ & 3.9 & 5.1 & 4.3 & $2.1-2.4$ & 1.5 & 1.1 & 0.7 & 3.1 & 3.5 & 4.1 \\
\hline $\begin{array}{c}D M P C+M 2 T M(x=0.06) \\
+\operatorname{Amt}(x=0.08)\end{array}$ & 4.1 & 5.3 & 4.4 & 2.4 & 1.6 & 1.3 & 0.9 & 3.3 & 3.7 & 4.4 \\
\hline $\begin{array}{c}D M P C+M 2 T M(x=0.03) \\
+A K 13(x=0.05)\end{array}$ & 4.1 & 5.4 & 4.5 & 2.4 & 1.7 & 1.4 & 0.9 & 3.3 & 3.8 & 4.4 \\
\hline $\begin{array}{c}D M P C+M 2 T M(x=0.06) \\
+A K 13(x=0.08)\end{array}$ & 4.0 & 5.3 & 4.5 & 2.3 & 1.6 & 1.3 & 0.9 & 3.3 & 3.7 & 4.3 \\
\hline
\end{tabular}

Table 7. Chemical shifts of $A m t$ and $A K 13$ observed in $1 \mathrm{H}$ NMR high-resolution spectra in gel and liquid phase at $15^{\circ} \mathrm{C}$ and $35^{\circ} \mathrm{C}$ respectively and $\mathrm{pH}$ 8.0.

\begin{tabular}{|c|c|c|c|c|}
\hline Sample & $\begin{array}{c}{ }^{1} \mathrm{H} \text { NMR } \\
\text { of } A m t \text { and } \\
\text { AK13 salts } \\
\text { in } \mathrm{D}_{2} \mathrm{O}\end{array}$ & Identification & $\begin{array}{l}15^{\circ} \mathrm{C} \\
{ }^{1} \mathrm{H} \\
\text { MAS } \\
\text { NMR }\end{array}$ & $\begin{array}{c}35^{\circ} \mathrm{C} \\
{ }^{1} \mathrm{H} \text { MAS } \\
\text { NMR }\end{array}$ \\
\hline$D M P C+M 2 T M(x=0.03)$ & - & - & - & - \\
\hline$D M P C+M 2 T M(x=0.06)$ & - & - & - & - \\
\hline $\begin{array}{c}D M P C+\operatorname{M2TM}(x=0.03) \\
+\operatorname{Amt}(x=0.05)\end{array}$ & $\begin{array}{l}2.1 \\
1.7 \\
1.6 \\
1.5 \\
\end{array}$ & $\begin{array}{c}3^{\prime}, 5^{\prime}, 7^{\prime} \\
4^{\prime}, 6^{\prime}, 10^{\prime} \\
2^{\prime}, 8^{\prime}, 9^{\prime} \\
-\mathrm{NH}_{2}\end{array}$ & - & - \\
\hline $\begin{array}{c}D M P C+\operatorname{M2TM}(x=0.06) \\
+\operatorname{Amt}(x=0.08)\end{array}$ & $\begin{array}{l}2.1 \\
1.7 \\
1.6 \\
1.5 \\
\end{array}$ & 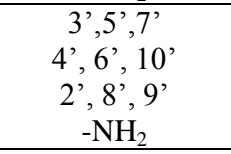 & - & 2.0 \\
\hline $\begin{array}{c}D M P C+M 2 T M(x=0.03) \\
+A K 13(x=0.05)\end{array}$ & $\begin{array}{c}2.9(\mathrm{t}) \\
2.1(\mathrm{bd}) \\
1.9 \\
1.7 \\
1.6 \\
1.4(\mathrm{bd}) \\
\end{array}$ & 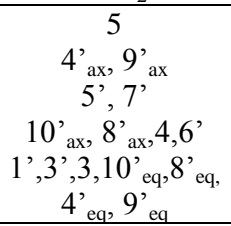 & - & 2.2 \\
\hline $\begin{array}{c}D M P C+M 2 T M(x=0.06) \\
+A K 13(x=0.08)\end{array}$ & $\begin{array}{c}2.9(\mathrm{t}) \\
2.1(\mathrm{bd}) \\
1.9 \\
1.7 \\
1.6 \\
1.4(\mathrm{bd})\end{array}$ & 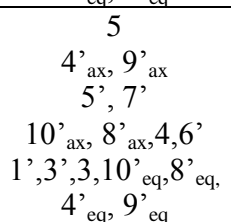 & - & $\begin{array}{l}2.1 \\
1.9 \\
1.8\end{array}$ \\
\hline
\end{tabular}

Table 8. Chemical shifts observed in ${ }^{13} \mathrm{C}$ CP-MAS NMR spectra of DMPC bilayers with and without Amt or $A K 13$ at $35^{\circ} \mathrm{C}$ and $\mathrm{pH} 8.0$.

\begin{tabular}{|c|c|c|c|c|c|c|c|c|c|c|c|c|c|}
\hline Sample & C1 & C2 & C3 & $\begin{array}{l}\text { C1', } \\
\text { C1" }\end{array}$ & $\begin{array}{l}\text { C2', } \\
\text { C2'" }\end{array}$ & $\begin{array}{l}\text { C3', } \\
\text { C3" }\end{array}$ & $\begin{array}{l}C\left(4^{\prime}-11^{\prime}\right), \\
C\left(4^{\prime \prime}-11^{\prime \prime}\right)\end{array}$ & $\begin{array}{l}\text { C12', } \\
\text { C12" }\end{array}$ & $\begin{array}{l}\text { C13', } \\
\text { C13" }\end{array}$ & $\begin{array}{l}\text { C14', } \\
\text { C14" }\end{array}$ & $\mathrm{N}\left(\mathrm{CH}_{3}\right)_{3}$ & C2"' & C1"' \\
\hline DMPC & 63.4 & 71.1 & 64.1 & 173.7 & 34.4 & 25.3 & 29.3-31.2 & 32.4 & 23.0 & 14.1 & 54.5 & 66.5 & 59.9 \\
\hline$D M P C+M 2 T M(x=0.03)$ & 63.3 & 71.0 & 64.0 & 173.7 & 34.3 & 25.2 & $28.7-31.3$ & 32.2 & 22.8 & 13.9 & 54.5 & 66.5 & 59.8 \\
\hline$D M P C+M 2 T M(x=0.06)$ & 63.6 & 71.2 & 64.3 & 173.9 & 34.6 & 25.4 & $29.4-31.3$ & 32.5 & 23.1 & 14.3 & 54.7 & 66.7 & 60.0 \\
\hline $\begin{array}{c}D M P C+M 2 T M(x=0.03) \\
+\operatorname{Amt}(x=0.05)\end{array}$ & 63.3 & 71.0 & 64.0 & 173.6 & 34.3 & 25.2 & $29.0-31.2$ & 32.2 & 22.8 & 13.9 & 54.4 & 66.4 & 59.7 \\
\hline $\begin{array}{c}D M P C+M 2 T M(x=0.06) \\
+\operatorname{Amt}(x=0.08)\end{array}$ & 63.5 & 71.1 & 64.3 & 173.9 & 34.5 & 25.4 & $28.8-31.1$ & 32.4 & 23.0 & 14.2 & 54.7 & 66.6 & 60.0 \\
\hline $\begin{array}{c}D M P C+M 2 T M(x=0.03) \\
+A K 13(x=0.05)\end{array}$ & 63.6 & 71.2 & 64.2 & 173.9 & 34.5 & 25.4 & 29.3-31.4 & 32.4 & 23.0 & 14.1 & 54.7 & 66.6 & 60.0 \\
\hline $\begin{array}{c}D M P C+M 2 T M(x=0.06) \\
+A K 13(x=0.08)\end{array}$ & 63.5 & 71.1 & 64.2 & 173.8 & 34.5 & 25.3 & $29.2-31.3$ & 32.4 & 23.0 & 14.1 & 54.6 & 66.6 & 60.0 \\
\hline
\end{tabular}

Table 9. Values of d-spacing and peak width of the lowest order reflections $f_{w h m}$ of SAXS and WAXS data of DMPC + M2TM $(x=0.03)$ in absence and presence of Amt or $A K 13$ at concentration $x=0.05$ and DMPC + M2TM ( $x=0.06)$ in absence and presence of Amt or $A K 13$ at concentration $x=0.08$ at $20{ }^{\circ} \mathrm{C}$ (top panel) and $30{ }^{\circ} \mathrm{C}$ (bottom panel), at $\mathrm{pH}=8.0$. 


\begin{tabular}{|c|c|c|c|c|}
\hline Sample & \multicolumn{2}{|c|}{ SAXS } & \multicolumn{2}{|c|}{ WAXS } \\
\hline $20^{\circ} \mathrm{C}$ & $\begin{array}{l}\text { d-spacing } \\
\text { (A) }\end{array}$ & $\begin{array}{c}\text { fwhm }_{q} \\
(1 / \AA)\end{array}$ & $\begin{array}{l}\text { d-spacing } \\
\text { (A) }\end{array}$ & $\begin{array}{c}\text { fwhm }_{q} \\
(1 / \AA)\end{array}$ \\
\hline$D M P C+M 2 T M(x=0.03)$ & $70.41(3)$ & $0.221(7)$ & $4.26(1)$ & $5.706(94)$ \\
\hline$D M P C+M 2 T M(x=0.06)$ & $67.12(2)$ & $0.154(5)$ & $4.26(1)$ & $3.887(76)$ \\
\hline $\begin{array}{c}D M P C+M 2 T M(x=0.03) \\
+\operatorname{Amt}(x=0.05)\end{array}$ & $68.12(5)$ & $0.228(9)$ & no peak & no peak \\
\hline $\begin{array}{c}D M P C+M 2 T M(x=0.06) \\
+\operatorname{Amt}(x=0.08)\end{array}$ & $68.38(4)$ & $0.292(10)$ & $4.27(1)$ & $5.638(159)$ \\
\hline $\begin{array}{c}D M P C+M 2 T M(x=0.03) \\
+A K 13(x=0.05)\end{array}$ & $69.16(3)$ & $0.204(6)$ & $4.35(2)$ & $5.392(112)$ \\
\hline $\begin{array}{c}D M P C+M 2 T M(x=0.06) \\
+A K 13(x=0.08)\end{array}$ & $66.81(2)$ & $0.177(5)$ & $4.28(1)$ & $3.94(75)$ \\
\hline
\end{tabular}

\begin{tabular}{|c|c|c|c|c|}
\hline Sample & \multicolumn{2}{|c|}{ SAXS } & \multicolumn{2}{|c|}{ WAXS } \\
\hline $30^{\circ} \mathrm{C}$ & $\begin{array}{c}\text { d-spacing } \\
\text { (Å) }\end{array}$ & $\begin{array}{c}\text { fwhm }_{q} \\
(1 / \AA)\end{array}$ & $\begin{array}{c}\text { d-spacing } \\
\text { (A) }\end{array}$ & $\begin{array}{c}\text { fwhm }_{q} \\
(1 / \AA)\end{array}$ \\
\hline$D M P C+M 2 T M(x=0.03)$ & $64.36(3)$ & $0.258(8)$ & $4.46(5)$ & $13.50(42)$ \\
\hline$D M P C+M 2 T M(x=0.06)$ & $64.35(2)$ & $0.199(5)$ & $4.25(1)$ & $9.79(15)$ \\
\hline $\begin{array}{c}D M P C+M 2 T M(x=0.03) \\
+A m t(x=0.05)\end{array}$ & $69.16(5)$ & $0.239(6)$ & no peak & no peak \\
\hline $\begin{array}{c}D M P C+\operatorname{M2TM}(x=0.06) \\
+\operatorname{Amt}(x=0.08)\end{array}$ & $\begin{array}{c}\text { unilamellar } \\
\text { bilayer }\end{array}$ & $\begin{array}{c}\text { unilamellar } \\
\text { bilayer }\end{array}$ & $4.12(4)$ & $17.43(47)$ \\
\hline $\begin{array}{c}D M P C+M 2 T M(x=0.03) \\
+A K 13(x=0.05)\end{array}$ & $64.5(6)$ & $0.23(6)$ & $4.46(6)$ & $11.6(5)$ \\
\hline $\begin{array}{c}D M P C+M 2 T M(x=0.06) \\
+A K 13(x=0.08)\end{array}$ & $65.3(3)$ & $0.211(8)$ & $4.27(1)$ & $12.35(24)$ \\
\hline
\end{tabular}




\section{Influenza A M2 Spans the Membrane Bilayer, Perturbs its Organization and Differentiates the Effect of Amantadine and Spiro[pyrrolidine-2,2'-adamantane] AK13 on Lipids}

Athina Konstantinidi, Maria Chountoulesi, Nikolaos Naziris, Barbara Sartori, Heinz Amenitsch, Gregor Mali, Tomaž Čendak, Maria Plakantonaki, Iro Triantafyllakou, Theodore Tselios, Costas Demetzos, David Busath, Thomas Mavromoustakos, ${ }^{*}$ Antonios Kolocouris ${ }^{*}$

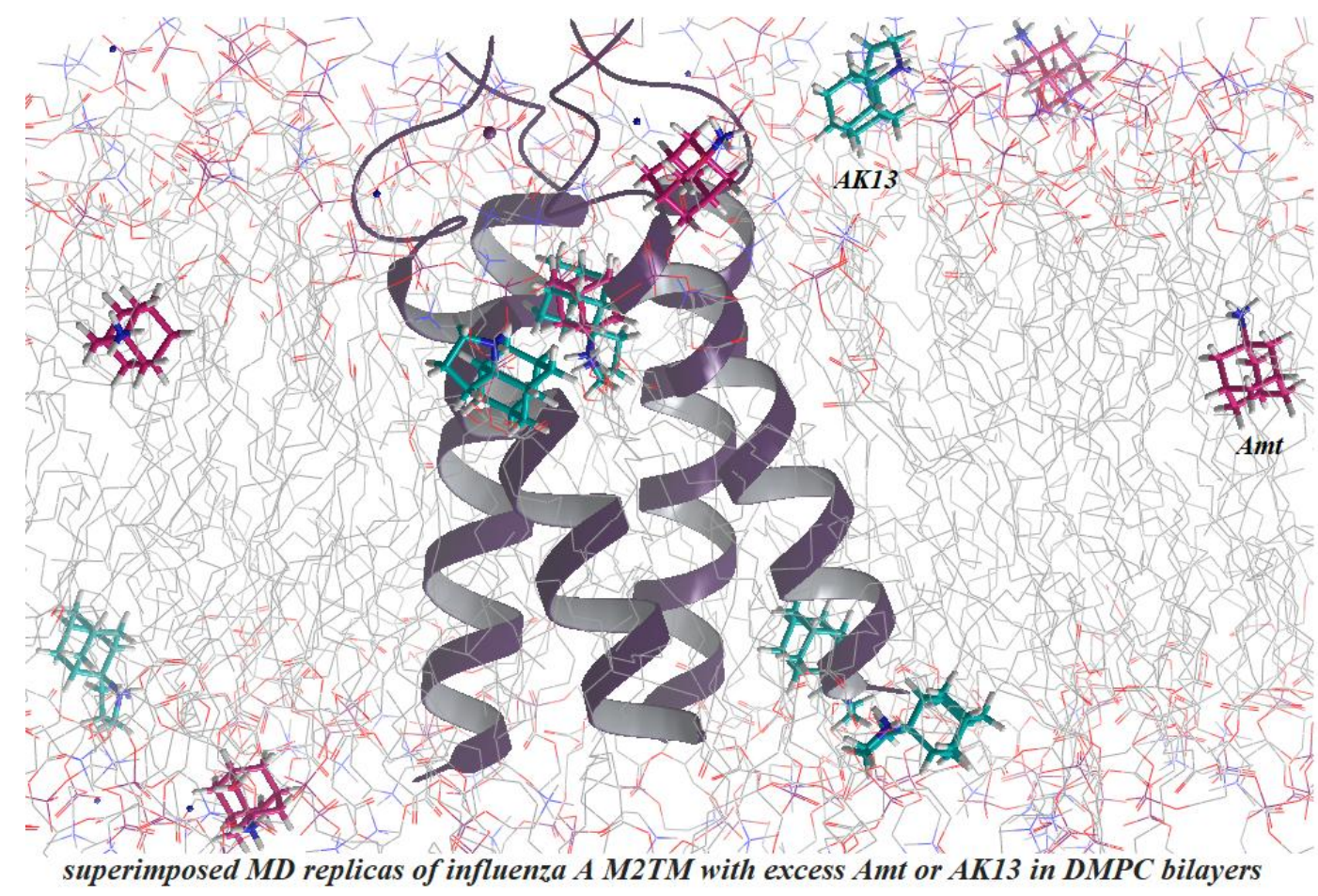

